\title{
THE USE OF NON-SACCHAROMYCES YEAST AND ENZYMES IN BEER PRODUCTION
}

\author{
- Research paper - \\ Monika CIOCH-SKONECZNY ${ }^{*}$, Krystian KLIMCZAK*, Paweł SATORA*, Szymon \\ SKONECZNY $^{* *}$, Marek ZDANIEWICZ* ${ }^{*}$, Aneta PATER*
}
*Department of Fermentation Technology and Microbiology, University of Agriculture, Kraków, Poland
*** Department of Chemical and Process Engineering, Cracow University of Technology, Kraków, Poland

\begin{abstract}
The objective of this paper was to test the potential of selected non-Saccharomyces strains for beer production, by using Saccharomyces cerevisiae as a control sample. For some of variants brewing enzymes were added to wort to increase the content of fermentable sugars. The non-Saccharomyces yeasts differed in the fermentation process rate. The basic beer physiochemical parameters were assessed, including: alcohol content, extract, free amino nitrogen, sugars, acidity, colour, and the profile of volatile compounds and metal ions. The use of enzymes caused an increase in alcohol and fusel alcohols concentration in beers obtained. Total acidity, free amine nitrogen content, colour and sugar content indicated that the tested non-Saccharomyces yeast allowed obtaining beers with the proper analytical parameters.
\end{abstract}

Key words: beer, non-Saccharomyces yeast, enzymes, fermentation, volatile compounds

\section{INTRODUCTION}

Most beers are fermented with pure Saccharomyces yeast cultures, with the exception of beers manufactured through spontaneous fermentation, such as Belgium sour beers (Lambic, Gueuze and Rodenbach) and American Coolship Ale. The popularity of the Saccharomyces yeast is connected with the effective production of large amounts of ethanol, a positive Crabtree effect, and high tolerance to the concentration of ethanol in the environment as well as other stress factors (Callejo et al. 2017).

However, together with the dynamic growth of the brewing sector on a global scale, new ways of manufacturing, to obtain a product with modified sensory characteristics, are in demand. Such expectations can be fulfilled by using nonSaccharomyces yeasts. Despite lower fermentation efficiency and lower resistance to ethanol in the environment, they often exhibit other metabolic activities, which may be decisive to the exceptional character of the product. Mixed nonSaccharomyces cultures or monocultures can be

Received: 16.07.2020.

Accepted in revised form: 20.10 .2020 mainly used to lend specific sensory features to products and produce low-calorie beers characterised by lower alcohol content or functional properties (Basso et al. 2016; Callejo et al. 2017).

Brewers may modify the sensory properties of their products through the application of specific malts, hops or adjuncts. However, it is the yeast strains that have a decisive impact on the final properties of the product. In the fermentation process, yeast produces ethanol and carbon dioxide as well as an entire array of aroma compounds, including esters, aldehydes, ketones and higher alcohols (Canonico et al. 2016).

The production of beer with different sensory features is among the most promising advantages of using non-Saccharomyces yeast. Due to metabolic differences, they may produce compounds with interesting sensory characteristics or in different amounts from those produced by Saccharomyces yeast. This approach has been followed for centuries in spontaneously fermented Belgian Lambic beers, where an important role is played by Brettanomyces bruxellensis yeast, producing high quantities of ethyl esters of lactic,

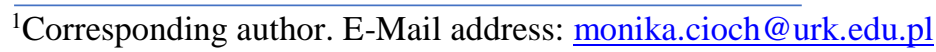


decanoic, octanoic and acetic acids. They also show high activity of hydroxycinnamic decarboxylase and vinylphenol reductase, which transform hydroxycinnamic acids mainly to 4ethylphenol and 4-ethylguaiacol with a characteristic aroma described as medical or saddlecloth (Vervoort et al. 2016). Some species, such as Wickerhamomyces anomalus and Kloeckera apiculata, contrarily to Saccharomyces, demonstrate high activity of $\beta$-glucosidases, which may release glucosidically bound volatile compounds, e.g. terpenes derived from hops and components from fruit or herbs added to the wort. A particularly high level of activity is demonstrated by Brettanomyces $\beta$-glucosidases. The application of the yeast would allow for releasing some previously unavailable volatile compounds. The approach is called "bioflavouring". Another option is to use strains synthesising large volumes of organic acids (mostly lactic acid) in sour beer production, without using lactic acid bacteria. This effect is possible by applying Lachancea thermotolerans yeast in brewing fermentation (Yeo \& Liu 2014; Basso et al. 2016; Domizio et al. 2016; Callejo et al. 2017).

Another possibility is to produce beer with lower alcohol content. The application of biological methods would avoid the costs of the equipment separating ethanol from the product and eliminate the issue of removing some volatile compounds with ethanol that may be found in some present solutions. Many Torulaspora delbrueckii strains demonstrate a low capacity for sugar fermentation, especially maltose and maltotriose, which allows for the manufacturing of beer characterised by significantly reduced alcohol content of approximately $0.9 \% \mathrm{v} / \mathrm{v}$. These strains synthesize large amounts of volatile compounds resulting in the distinctly fruity flavour of the product. In this respect, there are other promising microorganisms such as Wickerhamomyces subpelliculosus and Cyberlindnera saturnus. They are used in the production of low alcohol wine with acceptable sensory characteristics (Basso et al. 2016; Canonico et al. 2017).

The prevalence of obesity, and the resulting popularity of low-calorie products, has given rise to a new branch in the brewing sector - reduced calorie beers. One option is to use microorganisms, e.g. Dekkera/Brettanomyces, capable of hydrolysing and fermenting polysaccharides such as dextrins, which represent up to $80 \%$ of the residual extract. As a result, high degree of fermentation is achieved with a significant content of alcohol and decreased caloric value (Yeo \& Liu 2014; Basso et al. 2016).

The objective of this paper was to evaluate the potential of selected non-Saccharomyces strains for beer production. In the tests, an addition of amylolytic enzymes was applied in order to increase the content of fermentable sugars. The yeast species were selected on the basis of their natural occurrence in some alcohol fermentations and their biochemical features, with $S$. cerevisiae used as a control sample. In finished beers, the content of alcohol, extract, FAN, sugars, acidity, colour, as well as volatile compounds and ionic profiles, were determined.

The non-Saccharomyces yeast strains used for the research, although periodically mentioned in the scientific literature as yeast associated with the wine environment, have not been sufficiently characterized in terms of their use in brewing. The research presented in this paper will certainly enrich the literature related to the use of unconventional yeast in brewing.

\section{MATERIALS AND METHODS}

\section{Materials}

\section{Yeast strains}

Saccharomyces

Torulaspora

Wickerhamomyces

cerevisiae
delbrueckii

MH020215,

MG971248,

Brettanomyces bruxellensis and Metschnikowia pulcherrima MG970690 strains from the own collection of the Department of Fermentation Technology and Microbiology, University of Agriculture in Krakow were used in the study. Most of the strains used for the research were isolated from spontaneous grape fermentation.

\section{Inoculum preparation}

A three-step culture propagation was used to prepare the inoculum. During stage one, the strains were propagated on slants with Sabouraud agar (Biocorp, Poland) for $24 \mathrm{~h}$ at temperature $20^{\circ} \mathrm{C}$ and subsequently reinoculated to a $10 \mathrm{~mL}$ Sabouraud (Biocorp, Poland) liquid medium. After a subsequent $24 \mathrm{~h}$, they were dynamically propagated in $200 \mathrm{~mL}$ of Sabouraud liquid medium for $48 \mathrm{~h}$ in a shaker with water bath (120 $\mathrm{rpm}, 20^{\circ} \mathrm{C}$ ). After the propagation process was completed, the dry yeast mass was determined on a moisture analyser and, then the appropriate amount of slurry was centrifuged (10 minutes, 4 $989 \times \mathrm{g} / \mathrm{min})$. The sediment was washed with sterile 
water, again centrifuged under the same conditions and introduced into the wort.

\section{Wort preparation}

Wort was prepared by addition $7.9 \mathrm{~kg}$ of Viking Pilsner (https://www.marxam.pl, Kraków, Poland) malt to $23.7 \mathrm{~L}$ of water heated to $62.5^{\circ} \mathrm{C}$. The mash was heated up to $65^{\circ} \mathrm{C}$, kept at $65^{\circ} \mathrm{C}$ for 30 minutes, next the temperature was raised to $72^{\circ} \mathrm{C}$ and maintained for 30 minutes. At the end of the interval at $72^{\circ} \mathrm{C}$, the iodine test was performed to check if the starch had saccharified. To complete the mashing process, the mash was heated up to $78^{\circ} \mathrm{C}$ and kept at $78^{\circ} \mathrm{C}$ for 10 minutes. After the process, the mash was transferred to the filtering tank and left there for 30 minutes for the spent grain layer to form. The mash was filtered, receiving $40.5 \mathrm{~L}$ of wort with $9.1^{\circ} \mathrm{P}$ of extract. To ensure the clarity of the wort, the first $1 \mathrm{~L}$ of the obtained wort was filtered. The wort was boiled for an hour, adding $18.2 \mathrm{~g}$ of Cascade hop at the beginning of boiling (7 IBU). The resulting wort with the extract of $11^{\circ} \mathrm{P}$ was cooled down and inoculated.

\section{Inoculation and fermentation}

$300 \mathrm{~mL}$ of the prepared wort (extract $11^{\circ} \mathrm{P}, 7 \mathrm{IBU}$ ) were poured into Erlenmeyer flasks of $500 \mathrm{~mL}$. Yeast slurry was inoculated into the wort at the amount of $0.5 \mathrm{~g}$ d.w./L. The flasks were closed with glycerine-filled fermentation tubes and additionally sealed with parafilm. The fermentation was carried out for 18 to 20 days at $20^{\circ} \mathrm{C}$, in three repetitions. Attenuzyme Core (Novozymes. Brewing Handbook. 2013) and Fungamyl BrewQ (Novozymes. Brewing Handbook. 2013) were added to some samples before fermentation. Attenuzyme core breaks down complex sugars, mainly to glucose while Fungamyl BrewQ to maltose. Enzymes were determined on the basis of the producer's literature, doubling the recommended dose (Novozymes. Brewing Handbook. 2013). In the case of the Attenuzyme Core, the dose was $0.3 \mathrm{~mL} / \mathrm{L}$ of wort and $0.2 \mathrm{~mL} / \mathrm{L}$ in the case of Fungamyl BrewQ. The following combinations were applied (in three repetitions): $B$. bruxellensis, B. bruxellensis + Attenuzyme Core, B. bruxellensis + Fungamyl BrewQ, T. delbrueckii, T. delbrueckii+ Attenuzyme Core, T. delbrueckii+ Fungamyl BrewQ, $M$. pulcherrima, $M$. pulcherrima + Attenuzyme Core, $M$. pulcherrima + Fungamyl BrewQ, W. anomalus, W. anomalus + Attenuzyme Core, $W$. anomalus + Fungamyl BrewQ, S. cerevisiae, S. cerevisiae + Attenuzyme Core, S. cerevisiae + Fungamyl BrewQ.

\section{Methods \\ Determination of fermentation dynamics}

The fermentation rate was determined on the basis of a weight loss of samples weighted every $24 \mathrm{~h}$ with $0.01 \mathrm{~g}$ accuracy. Results from three independent repetitions were presented as a percentage loss of the fermentation media mass.

\section{Determination of real extract and alcohol content}

Alcohol concentration in final beer was determined using the pycnometric method. For this purpose, the sample after fermentation was distilled. The obtained distillate was filled up to $100 \mathrm{~g}$ with distilled water, its density was determined and the concentration of ethanol was read from the adequate tables (Analytica EBC Methods 9.2.1, Analytica EBC Methods 9.4), (Analytica EBC, European Brewery Convention, 1998).

\section{Determination of titratable acidity}

The potentiometric method was applied to determine titratable acidity, titrating a sample with $0.1 \mathrm{M} \mathrm{NaOH}$ solution to obtain $\mathrm{pH}=8$.

\section{Determination of FAN content}

Free amino nitrogen (FAN) was measured using ninhydrin-based methods with the use of the absorbance measurement at $570 \mathrm{~nm}$ (Beckman DU-650 UV-Vis) according to the method: 8.10 Free Amino Nitrogen in wort by Spectrophotometry (IM) (Analytica EBC, European Brewery Convention, 1998).

\section{Determination of colour}

The colour of the filtered samples was determined spectrophotometrically (Beckman DU-650 UVVis) at a wavelength of $430 \mathrm{~nm}$ according to Analytica EBC Methods 8.5 and Analytica EBC Methods 9.6).

Determination of sugar content (HPLC), volatile compounds (SPME-GC-MS) and Absorptive Atomic Spectrometry (AAS)

All determinations were done according to Zdaniewicz et al. (2020).

\section{Statistical analysis}

The results presented in the study were the means of three independent repetitions with the determination of the standard deviation. The data were analysed with the variance analysis (ANOVA) in order to establish the significance of the tested parameters. Statistically significant differences between the means were verified with the Duncan's test using the Statistica 10 statistical software (StatSoftPolska, Kraków). 


\section{RESULTS AND DISCUSSION}

\section{Fermentation dynamics}

The data on the Figure 1 demonstrates the significant differences of the fermentation process in the analysed samples. The final losses of mass are similar in all variants without added enzymes. Batches inoculated with $S$. cerevisiae and $B$. bruxellensis presented the shortest period of yeast adaptation to the new environment and were the fastest in fermentation of most sugars. In the case of $M$. pulcherrima and $W$. anomalus, adaptation time was significantly longer and a rapid loss of mass started within approximately 3 days after the inoculation and its duration was approximately 6 days. T. delbrueckii yeast, however, conducted a slow fermentation for the first 8 days followed by a phase of intensive fermentation. Final mass losses were similar for all samples. Similar trends were observed in the case of variants with Fungamyl BrewQ application preparation (Figure 2).

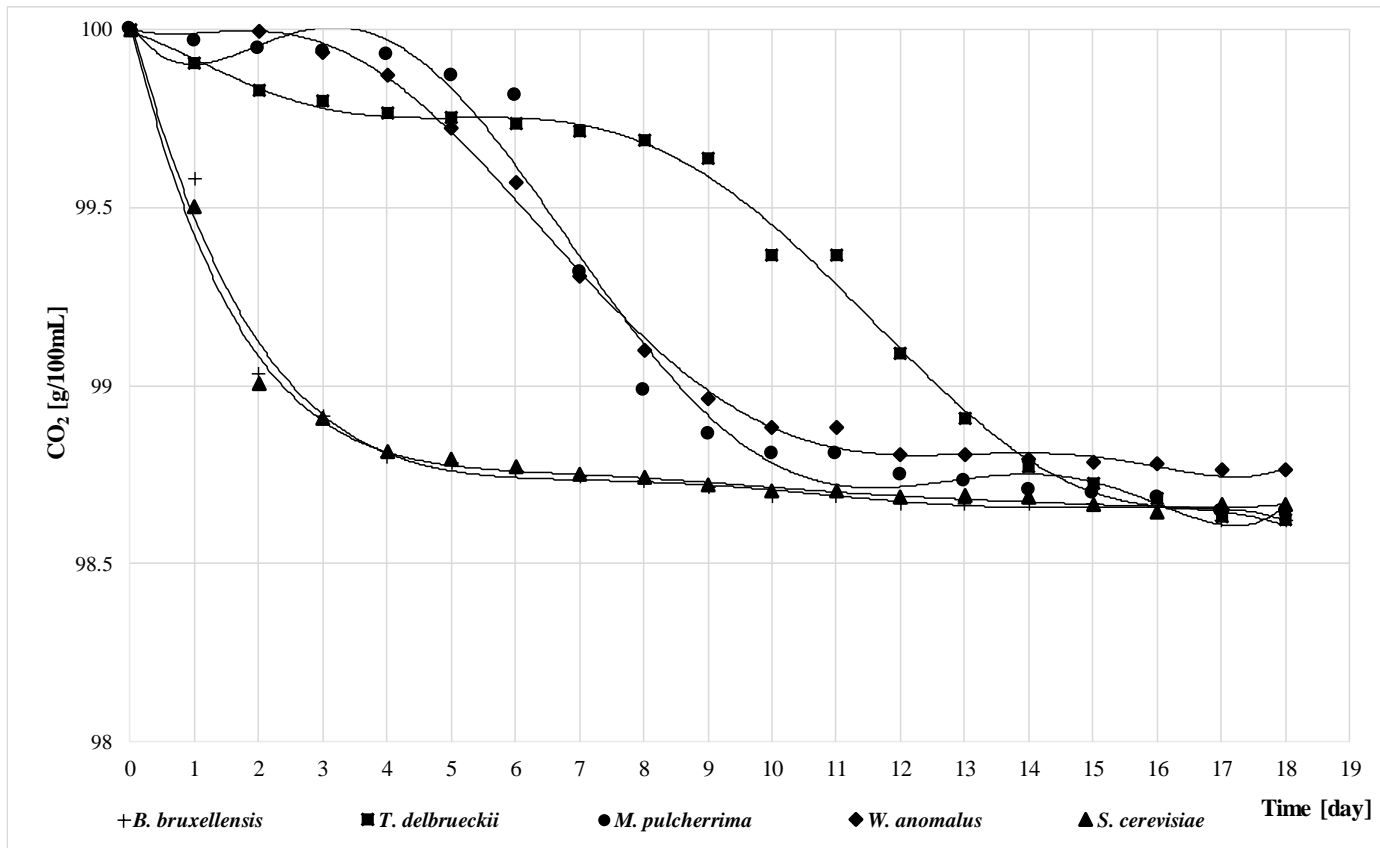

Figure 1. The fermentation dynamics for samples without enzyme addition

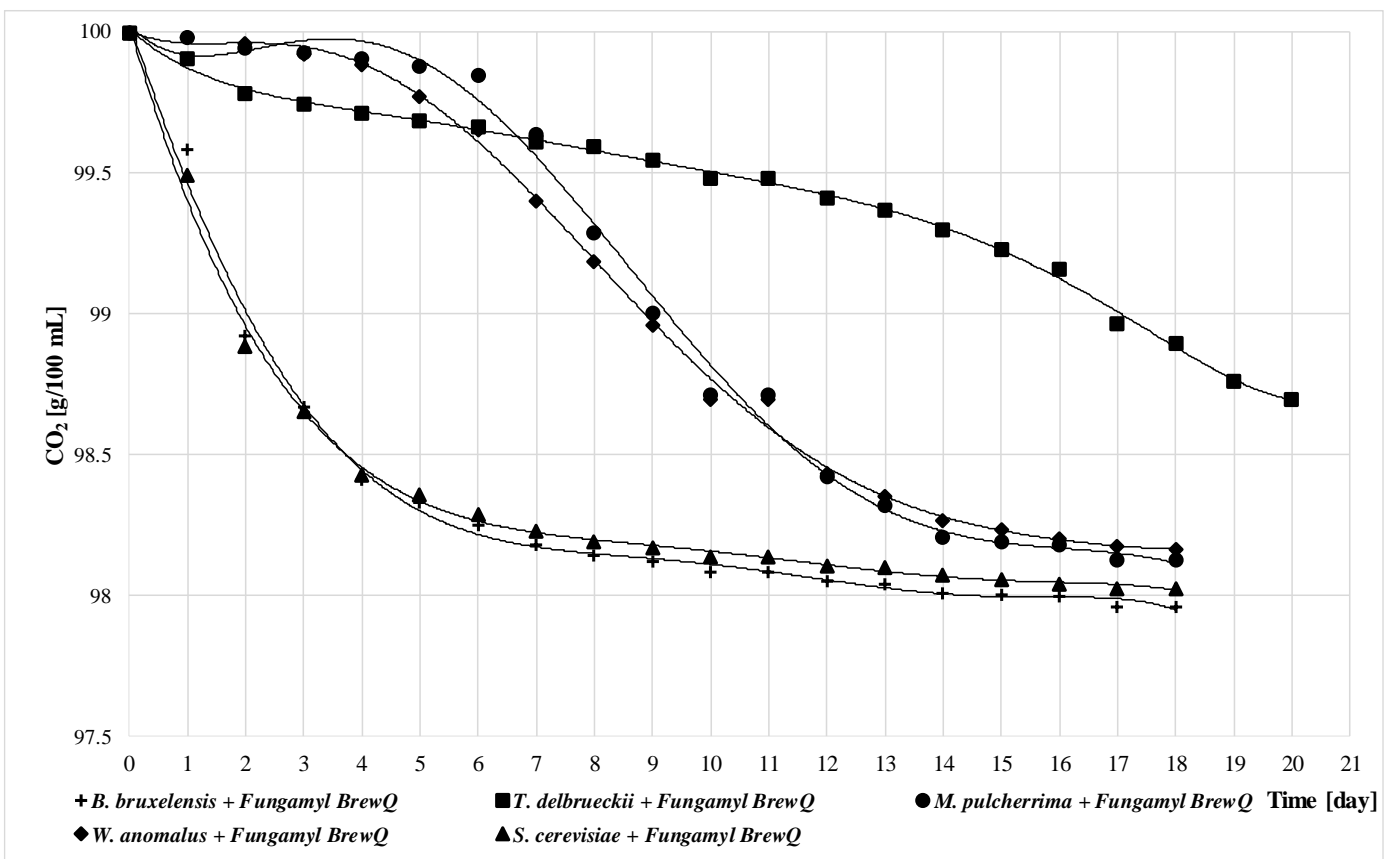

Figure 2. The fermentation dynamics for samples with the addition of Fungamyl BrewQ enzyme 
The preparation contains fungal $\alpha$-amylases, which break down the non-fermentable sugars present in the wort mostly to maltose. Samples inoculated with $S$. cerevisiae and B. bruxellensis demonstrated the most rapid fermentation rate and early completion of the key stage of fermentation, which lasted approximately 8 days. M. pulcherrima and $W$. anomalus required longer time to start fermentation and the intense part of the process lasted approximately 11 days. The lowest fermentation rate was reported for T. delbrueckii.

The fermentation process of the samples with Attenuzyme Core application (glucoamylase releasing mainly glucose) (Figure 3 ) looks similar to the previous variants (Figures 1 and 2), with the exception of $T$. delbrueckii. Contrary to earlier trials, the microorganism started fermentation quickly as the samples inoculated with Saccharomyces and Brettanomyces, it demonstrated a similar fermentation rate and what was interesting - samples obtained with its participation were characterised by the highest loss of mass among the tested variants (Figure 3). Losses of mass for other microorganisms were similar to the previously described cases. A graph of mean losses in mass (Figure 3) shows that the analysed B. bruxellensis strain demonstrates a course of fermentation very similar to $S$. cerevisiae, in spite of the general assumption that the yeasts are characterised by a slower fermentation rate (Meneghin et al. 2013).
W. anomalus and M. pulcherrima had a longer adaptation time and slower progress of fermentation compared to the control sample. The mean mass losses similar to $S$. cerevisiae, in variants inoculated with the above-mentioned yeast, suggest that similarly to brewing yeast, the species have ability to use sugars contained in the wort. Samples inoculated with $T$. delbrueckii presented a different result. In the standard brewing wort (no enzymes addition) and in the wort with higher maltose content, mass losses are significantly lower when compared to other batches. However, when the enzyme releasing glucose from non-fermentable sugars was applied to the wort, the mass change became significantly similar to the process observed for $S$. cerevisiae. It suggests that the $T$. delbrueckii strain used in the process is characterised by a relatively low maltose fermentation activity. The fermentation dynamics graph demonstrates that the analysed nonSaccharomyces yeasts ferment more slowly than Saccharomyces (except for B. bruxellensis) but are capable to obtain wort fermentation degree at the levels similar to $S$. cerevisiae. However, this process may require more time than that the one involving brewing yeast. It creates the opportunity for brewing beers of lower alcohol concentration when appropriate fermentation conditions are applied.

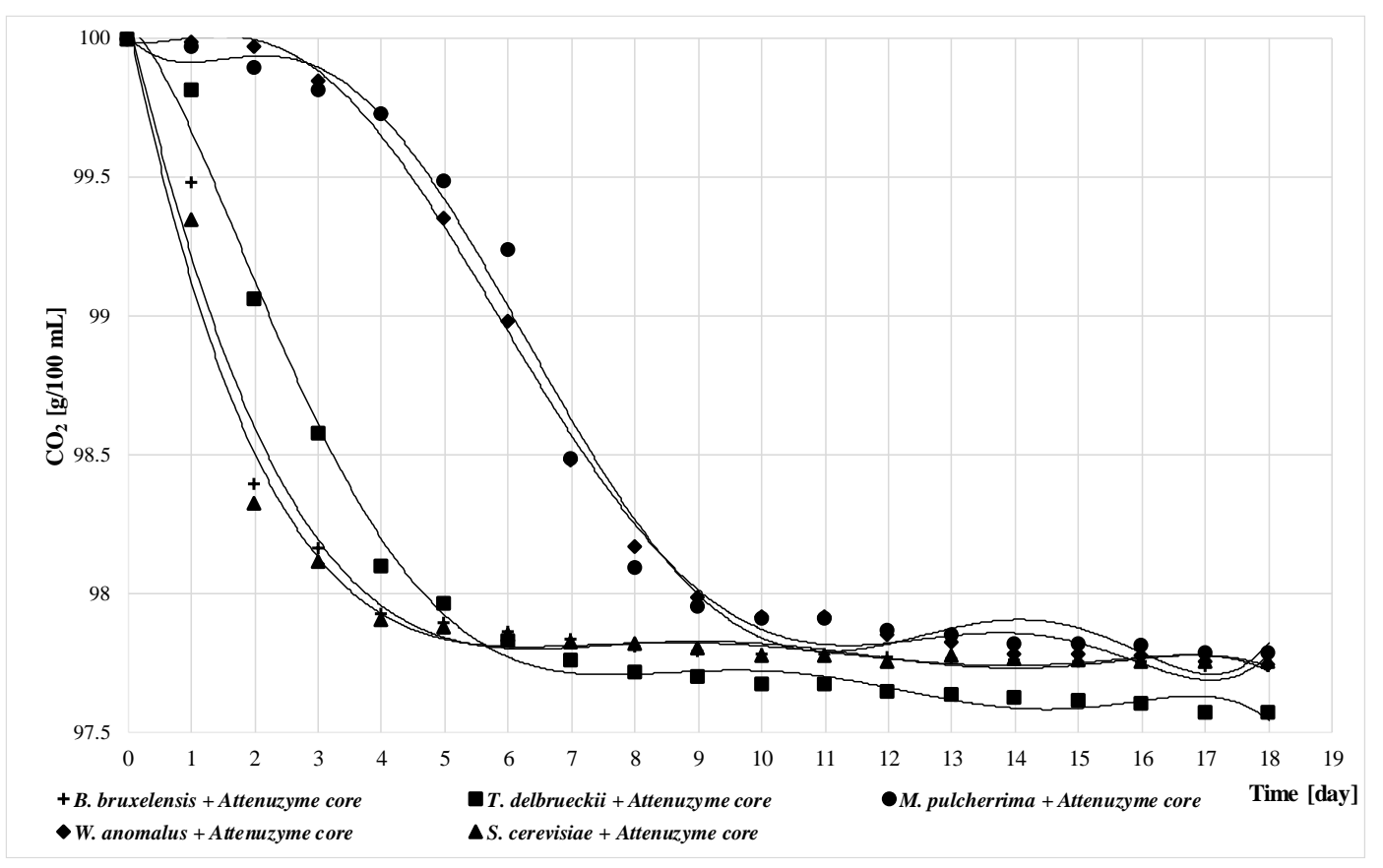

Figure 3. The fermentation dynamics for samples with the addition of Attenuzyme Core enzyme 


\section{Physicochemical parameters}

\section{Alcohol and extract}

Out of all the tested enzyme-free variants, all yeast species produced different quantities of alcohol $(2.40-2.66 \% \mathrm{v} / \mathrm{v})$ (Figure 4$)$. The content of extract ranged from 4.63 to $4.87^{\circ} \mathrm{P}$, except for a sample with $B$. bruxellensis, where its content was significantly lower, i.e. $4.30^{\circ} \mathrm{P}$ (Figure 5). This is in line with the previous assumption that the species demonstrate similar assimilation capacities with respect to sugars occurring in the wort, such as $S$. cerevisiae. The significantly lower content of the extract in the fermented by $B$. bruxellensis sample may be related to the activity of $\alpha$ glucosidase occurring in the species, allowing for the assimilation of the polysaccharides. Traditionally, the content of the residual extract in beers ranges from below $1 \%$ in deeply attenuated beers, e.g., of the lambic type, to nearly $10 \%$ in sweet barley wine.

The high content of residual sugars gives the products a full, in some cases sweet, taste, while their low content results in a lighter mouthfeel (Colicchio 2012). The significant residual quantity of the extract, even in beer fermented with $S$. cerevisiae, suggests relatively low content of fermented sugars.

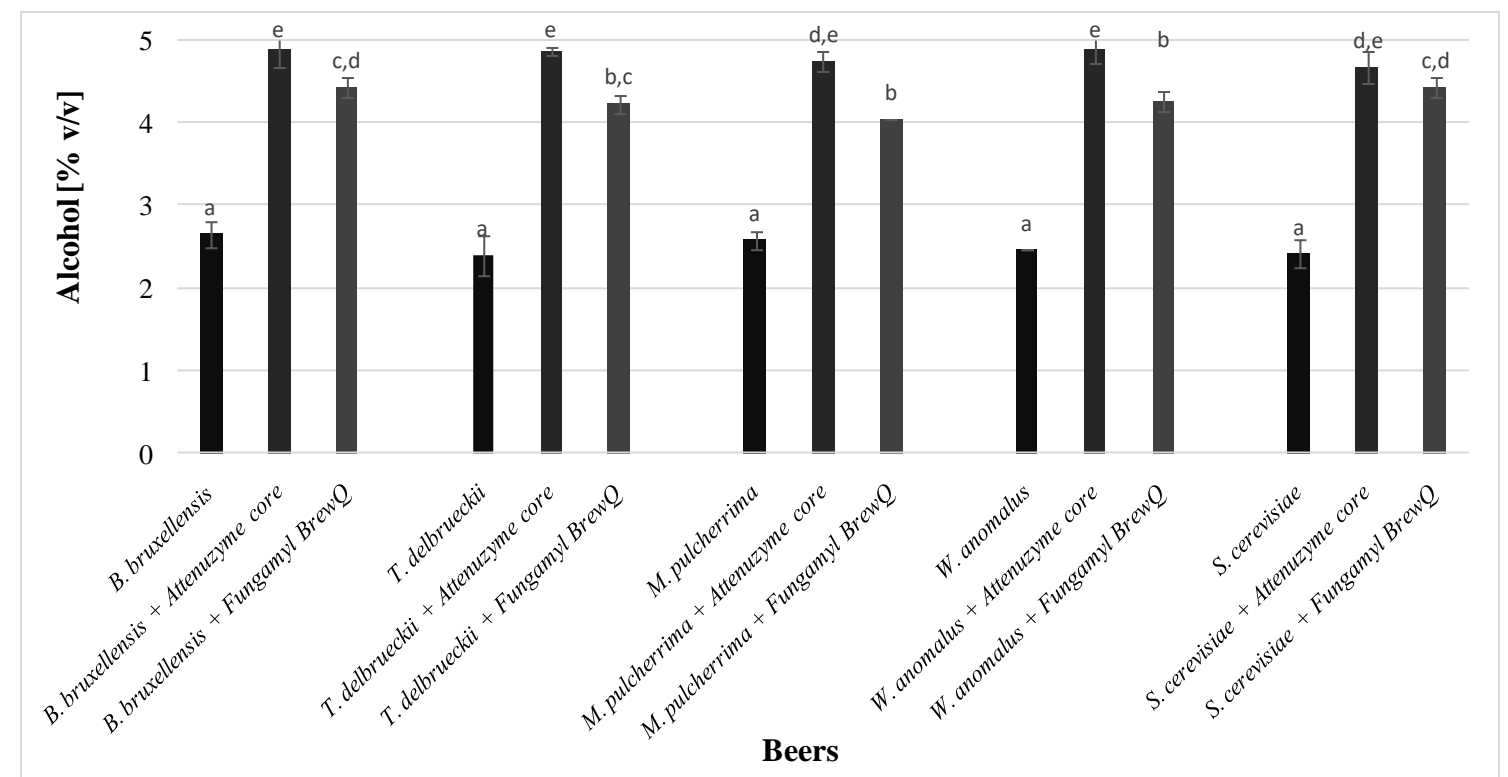

Figure 4. Alcohol content in the analysed beers

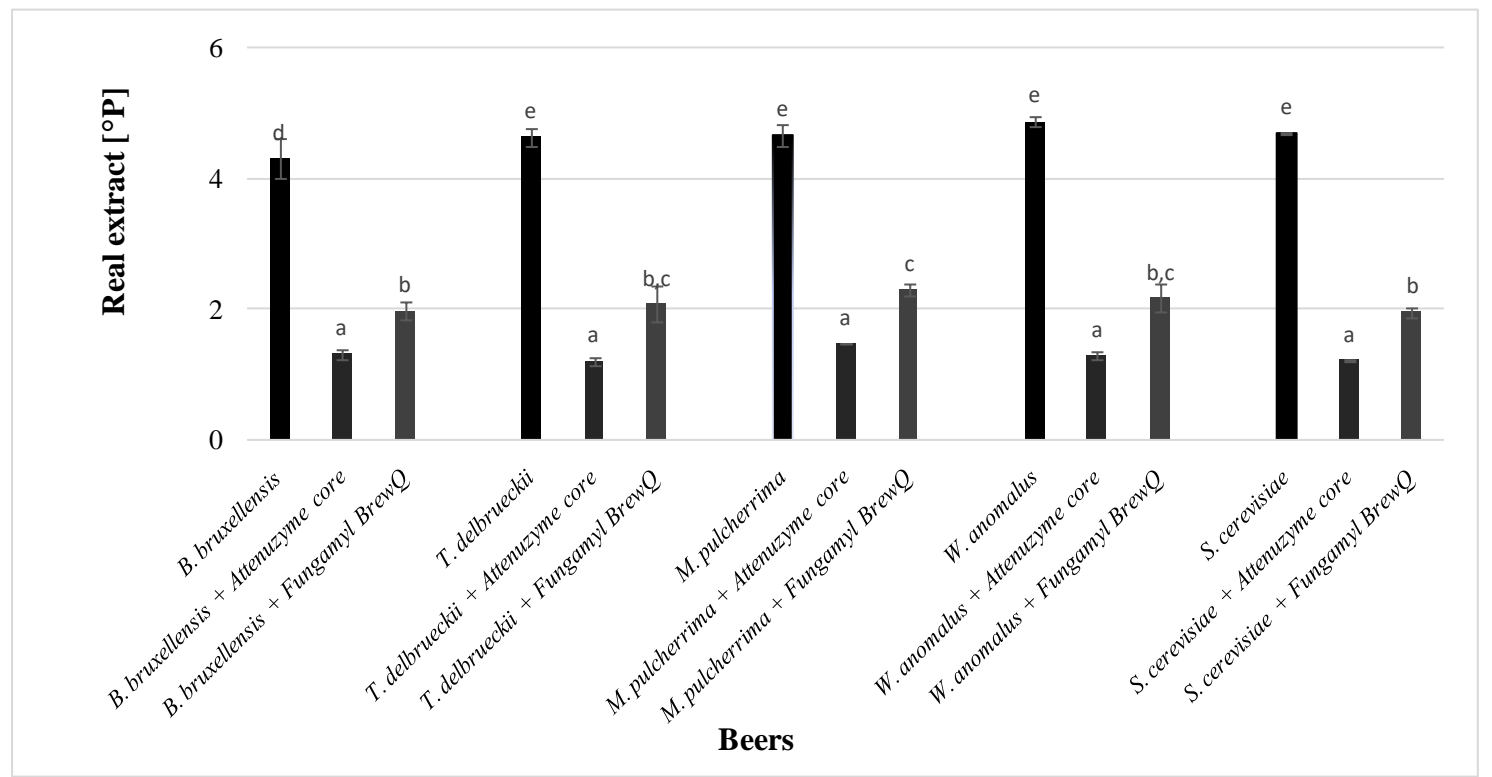

Figure 5. Real extract content in analysed beers 
Samples with Attenuzyme Core enzyme application were characterised by the extract ranging from $1.21-1.47^{\circ} \mathrm{P}$ (Figure 5). Such low content of the extract allowed for classifying the beer among the highly attenuated beers. The addition of the enzyme should increase conversion most, usually unfermented sugars, into glucose. A significantly lower content of the extract compared to enzyme-free samples, and higher alcohol content, proved that sugars have been decomposed to glucose. Thus, an environment consisting largely of glucose was created which, in turn, led to producing a higher amount of alcohol. For nonSaccharomyces yeast, the alcohol content was similar and ranged from $4.75-4.9 \% \mathrm{v} / \mathrm{v}$ (Figure 4). It is interesting that the content of alcohol in the beer fermented with $S$. cerevisiae was significantly lower and reached $4.68 \% \mathrm{v} / \mathrm{v}$ (Figure 4).

As expected, by using Fungamyl BrewQ enzyme, beers with significantly higher alcohol content were produced (Figure 4), however large variation between samples was detected. The highest concentration of alcohol, equal to the concentration in the control, was obtained for B. bruxellensis, at $4.44 \% \mathrm{v} / \mathrm{v}$ for both variants (Figure 4 ).

The extract level did not differ significantly and ranged from $1.95-1.97^{\circ} \mathrm{P}$ (Figure 5). Beers fermented with $T$. delbrueckii and $W$. anomalus had lower alcohol content, $4.24 \% \mathrm{v} / \mathrm{v}$ and $4.27 \%$ $\mathrm{v} / \mathrm{v}$, respectively (Figure 4). Again, the extract content did not differ significantly and ranged from 2.07 to $2.16^{\circ} \mathrm{P}$ (Figure 5). The lowest concentration of alcohol, $4.05 \% \mathrm{v} / \mathrm{v}$ (Figure 4), was obtained in the sample inoculated with $M$. pulcherrima, with the extract content of $2.29^{\circ} \mathrm{P}$ (Figure 5). Higher extract content and lower alcohol concentration in the samples with the addition of the Fungamyl BrewQ enzyme- compared to the samples with the Attenuzyme Core addition- were due to the way the enzymes acted. Attenuzyme Core is a more aggressive enzyme, and hence, is capable of decomposing more compounds to monosaccharides (Novozymes. Brewing Handbook. 2013).

In the samples obtained without the addition of enzymes, ethanol content was similar as a result of a low content of fermentable sugars (Figure 4). In the variants with the enzyme, the difference is due to the higher sugar content that can be used by the yeast. The samples with added Attenuzyme Core enzyme did not demonstrate any difference in alcohol content except for the batch inoculated with $S$. cerevisiae. This may indicate a similar degree of sugar fermentation by the studied species. Our research results contradicted the generally accepted assumption that non-
Saccharomyces yeasts are characterised by a low fermentation activity. In terms of alcohol content, higher differences was found in the batches with Fungamyl BrewQ enzyme. It could have been caused by different maltose utilization ability of the analysed species. These differences confirm various changes in the total mass losses of the samples during the fermentation of wort (Figure 2). Beers inoculated with $B$. bruxellensis were characterised by the highest alcohol content on average and even above the control sample, $S$. cerevisiae, in a sample with added Attenuzyme Core (Figure 4). The high fermentative efficiency of $B$. bruxellensis is not surprising due to its significant importance in the spontaneous fermentation of lambic beers (Schifferdecker et al. 2014; Canonico et al. 2016).

The beer produced using the T. delbrueckii strain, in the Fungamyl BrewQ enzyme variant, was characterised by lower content of alcohol from the control sample. However, considering the graph of fermentation dynamics (Figure 2), the production of such quantity of alcohol was the longest lasting of all the samples. This may indicate the low ability to utilise maltose by the tested strain. Beer inoculated with $T$. delbrueckii with the Fungamyl BrewQ enzyme contained $4.24 \% \mathrm{v} / \mathrm{v}$ of alcohol, which is one of the highest contents among the current data presented in literature. In the experiments performed by Canonico et al. (2017), beer fermented with $T$. delbrueckii contained $2.62 \% \mathrm{v} / \mathrm{v}$ of alcohol, similar to trials of Michel et al. (2016) $-0.83-4.00 \% \mathrm{v} / \mathrm{v}$. Beer produced by Tatardis et al. (2016) with T. delbrueckii, was characterised by alcohol content similar to the obtained results $(4.2 \% \mathrm{v} / \mathrm{v})$. These results demonstrate highly diversified fermentation capacities of different strains of $T$. delbrueckii species. The analytical parameters of beers from $W$. anomalus fermentations are very similar to the results for $T$. delbrueckii (Figures 4 and 5). Similarly, as in the case of other species, so far, there have been no publications testing their behaviour in the brewing sector. However, results suggest that the microorganism, similarly as others tested in the research, may be used in the fermentations.

\section{Titratable acidity}

Samples obtained without added enzyme were characterised by relatively low total acidity ranging from 2.28 to $2.76 \mathrm{~mL} 1 \mathrm{M} \mathrm{NaOH} / 100 \mathrm{~mL}$ of beer (Figure 6). An exception was W. anomalus samples, where a higher acidity of beers at 3.09 $\mathrm{mL} 1 \mathrm{M} \mathrm{NaOH} / 100 \mathrm{~mL}$ was found. Results differed more widely for variants with the Attenuzyme 
Core enzyme application. The lowest acidity (1.97 $\mathrm{mL} 1 \mathrm{M} \mathrm{NaOH} / 100 \mathrm{~mL}$ ) was achieved for a sample with $M$. pulcherrima. The result was lower than in beer without the added enzyme. In terms of acidity, samples fermented with $B$. bruxellensis did not differ from samples fermented without the enzyme. Beers inoculated with $T$. delbrueckii, $W$. anomalus and $S$. cerevisiae were characterised by the highest level of acidity in the group, ranging from 2.93 to $3.05 \mathrm{~mL} \mathrm{1M} \mathrm{NaOH} / 100 \mathrm{~mL}$ (Figure 6).

In the case of batches with the Fungamyl BrewQ enzyme, the sample inoculated with $B$. bruxellensis was characterised by the lowest acidity in the group of $2.10 \mathrm{~mL} 1 \mathrm{M} \mathrm{NaOH} / 100 \mathrm{~mL}$ (Figure 6). Wort inoculated with $T$. delbrueckii reached an acidity level identical to the level in sample without enzyme addition. In other samples, inoculated with $M$. pulcherrima, W. anomalus and $S$. cerevisiae a similar acidity level - the highest of all the samples - ranging from 4.45 to $5.06 \mathrm{~mL} 1 \mathrm{M}$ $\mathrm{NaOH} / 100 \mathrm{~mL}$ (Figure 6) was detected. The results suggested an increased production of acids in beers, with a higher concentration of maltose.

Total acidity is a parameter that is not standardised in the case of brewing fermentation. However, it provides some information on the general content of acid substances in the product. This parameter is more useful than $\mathrm{pH}$ in forecasting the impact of acid content on the product flavour (Nielsen 2005). The results showed that beers produced with the use of selected strains other than the Saccharomyces species did not significantly differ in terms of acidity from the control sample with $S$. cerevisiae. Of all the results, B. bruxellensis was characterised by low total acidity, ranging from 2.87 to $3.071 \mathrm{M} \mathrm{NaOH} / 100 \mathrm{~mL}$ of beer (Figure 6). Contrary to other samples, samples fermented with
B. bruxellensis demonstrated low differentiation. Although it is traditionally believed that yeast produces significant quantities of acetic acid, requires aerobic conditions. Under anaerobic conditions, cells either do not produce acetic acid or synthesize its minimal quantity (Uscanga et al. 2003). Variants inoculated with $T$. delbrueckii were characterised by insignificantly higher acidity of 2.76-3.15 1M NaOH/100 mL of beer (Fig. 6). According to Sadineni et al. (2012), wines produced via inoculation with this species have lower or similar acidity as those inoculated with $S$. cerevisiae, which corresponds to the result obtained using the Attenuzyme Core enzyme. Beers inoculated with $M$. pulcherrima were characterised by the significant differentiation of acidity within the range of 2.76 to $4.451 \mathrm{M}$ $\mathrm{NaOH} / 100 \mathrm{~mL}$ (Figure 6). Acidity of the sample with the Attenuzyme Core enzyme was similar to the analogous variant of $S$. cerevisiae that is consistent with the data presented in literature (Sadineni et al. 2012). Beers produced with $W$. anomalus reached acidity levels ranging between 3.09 and $4.481 \mathrm{M} \mathrm{NaOH} / 100 \mathrm{~mL}$ of the sample (Figure 6), which, on average, was the highest of all tested non-Saccharomyces yeasts. In the wine fermentations carried out by Cordero-Bueso et al. (2011), wines inoculated with $W$. anomalus reached lower acidity values than those in the corresponding samples for S. cerevisiae. Furthermore, as mentioned above, Osburn et al. (2018) reported that some $W$. anomalus species may produce a sufficient quantity of acids to manufacture sour beers. Results indicating similar acidity for beers produced by fermenting with $W$. anomalus and $S$. cerevisiae monocultures may be related to the properties of the strains used.

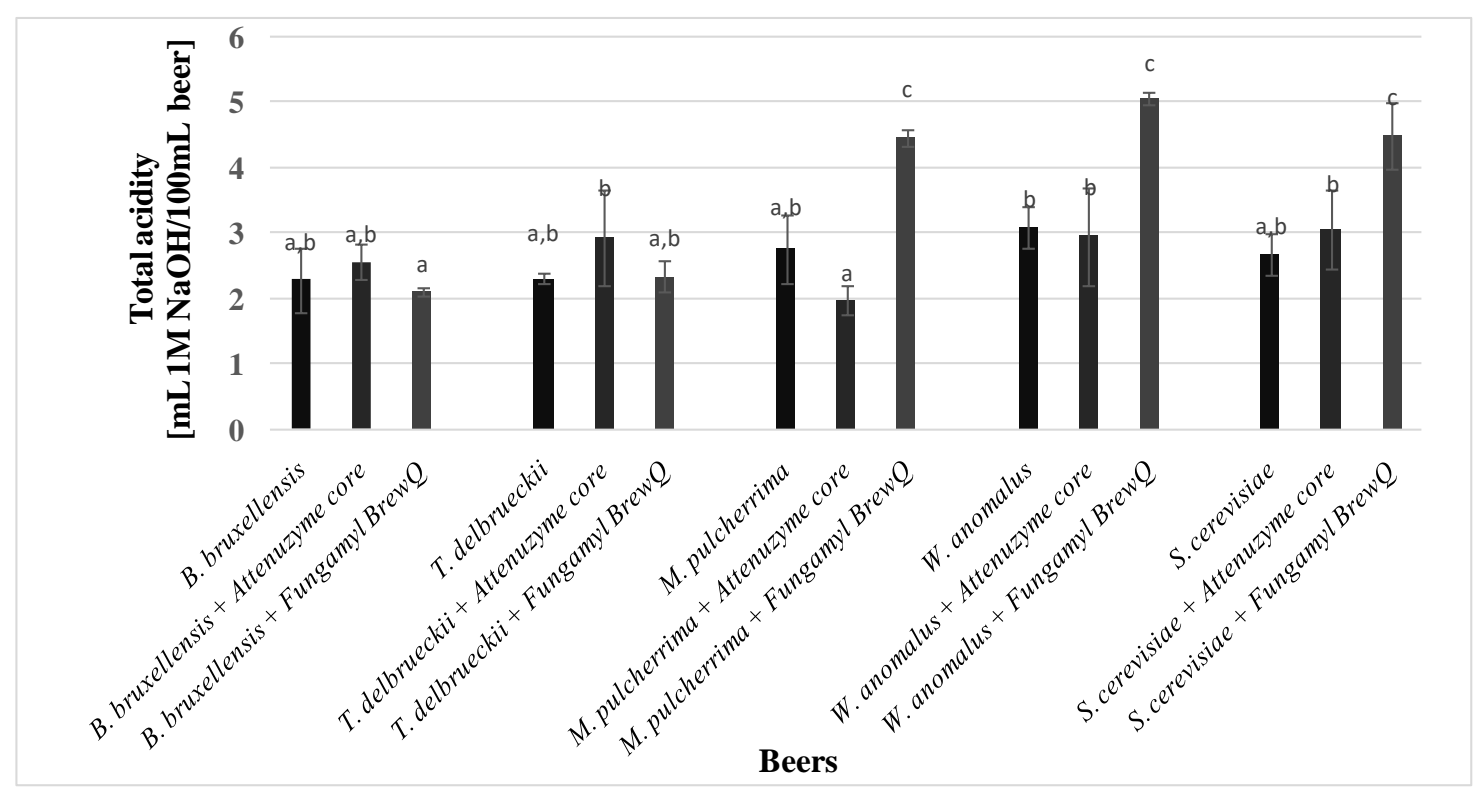

Figure 6. Total acidity content in analysed beers 


\section{FAN content}

Free amino nitrogen is the parameter used for all nitrogen compounds assimilable by yeast during the fermentation process, such as free amino acids, low-particulate peptides and ammonia (Starcher 2001). The amino acid composition and content in wort have a significant impact on higher alcohol production in the Ehrlich pathway (Hill \& Stewart 2019). The wort used in the test was characterised by a relatively low content of free amino nitrogen of $98.12 \mathrm{mg} / \mathrm{L}$ (Figure 7). It was probably related to the quality of the malt used in its preparation. Depending on the source, it is assumed that the minimum FAN content should reach $100 \mathrm{mg} / \mathrm{L}$ or 150 mg/L (Fix 1999; Hill \& Stewart 2019). Any lower level may result in the prolonged time of launching fermentation or incomplete fermentation, high production of undesirable volatile compounds and low concentration of esters. However, considering the graph presenting changes in mass during fermentation and significant residual FAN in the finished beers, it can be assumed that the low level of nitrogen in wort was of insignificant importance.

All samples with $S$. cerevisiae demonstrated its higher consumption and the volume of residual FAN after fermentation for these samples was considerably lower than for beers fermented with non-Saccharomyces yeast (Figure 7). The above suggests that these species demonstrated a lower demand for nitrogen compounds than $S$. cerevisiae.
Similar results were reported by Bellut and Arendt (2019) for fermentation with T. delbrueckii. This may allow for using selected non-Saccharomyces species for fermentation of worts containing little nitrogen substances, e.g. those produced from sorgo (Dlamini et al. 2015). In the case of all samples, with the exception of that inoculated with $W$. anomalus, dependence can be observed when the variants with the added Attenuzyme Core were characterised by increased residual FAN. The results showed that the degree of consumption of nitrogen compounds is significantly affected by the profile of sugars in the wort. Among the variants with no enzymes added, the highest FAN consumption was reported for $M$. pulcherrima, the lowest for B. bruxellensis and T. delbrueckii. The sample with $W$. anomalus showed the lowest decrease in FAN by an average of $10 \mathrm{mg} / \mathrm{L}$ compared to the unfermented wort (Figure 7).

The dependencies are different for samples obtained both when using the Attenuzyme Core enzyme as well as the Fungamyl BrewQ enzyme, where they were uniform for both enzymes. In the case of samples with enzyme addition, the highest FAN consumption was reported in the batch inoculated with $W$. anomalus. Beers fermented with $M$. pulcherrima and $B$. bruxellensis, respectively, demonstrated a lower level, while the lowest consumption was reported for $T$. delbrueckii (Figure 7).

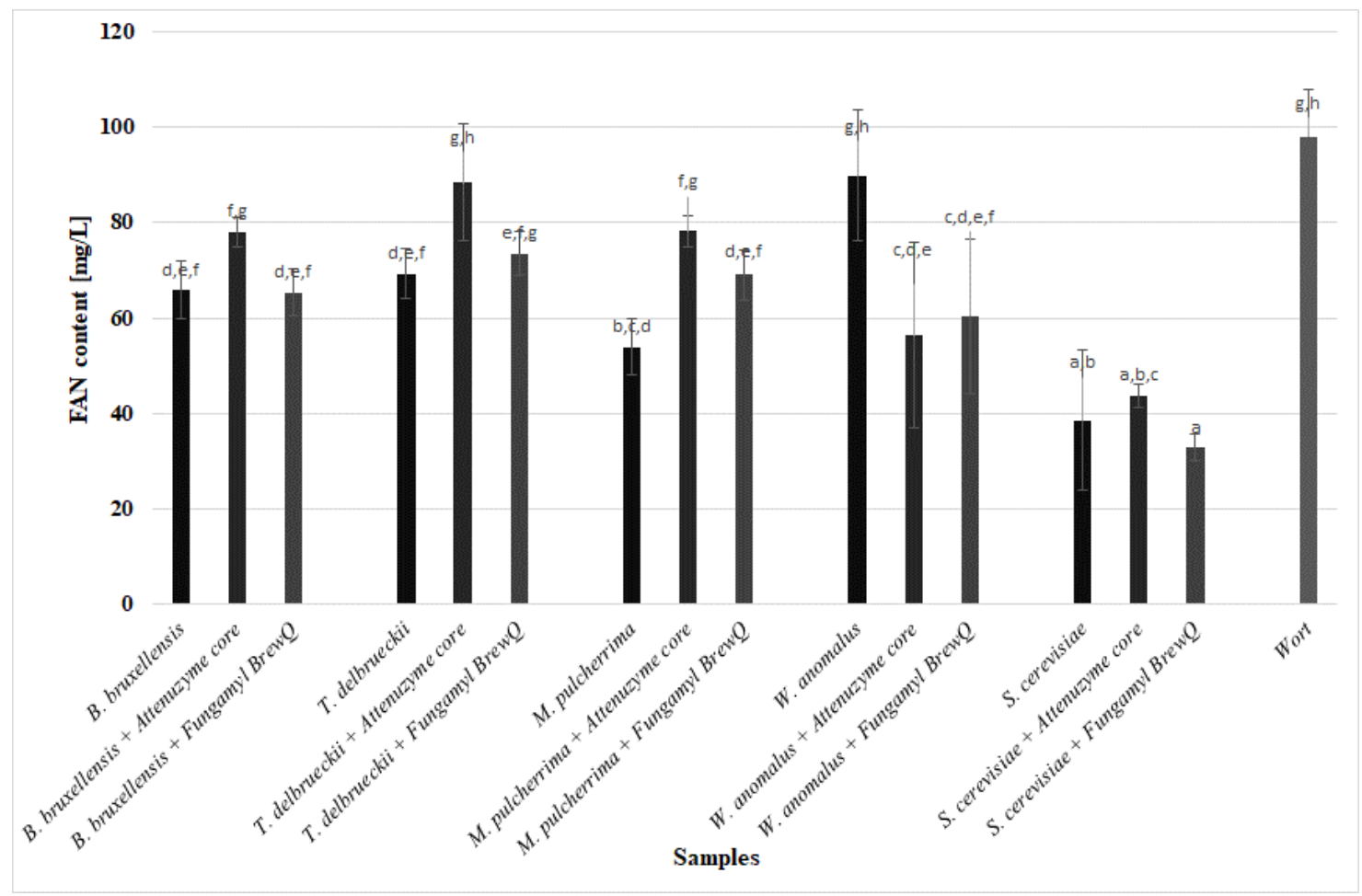

Figure 7. Free amino nitrogen (FAN) content in analysed beers 
No studies have been published so far comparing FAN consumption by the tested yeast species in the brewing fermentations. According to Rollero et al. (2018), during fermentation of a synthetic medium, $W$. anomalus had a slightly lower FAN consumption than $S$. cerevisiae, which is consistent with the results obtained for the samples with added enzymes. The very low consumption of FAN in the sample without enzymes might be related to the low content of fermentable sugars. Low FAN utilization by $B$. bruxellensis, $T$. delbrueckii and $M$. pulcherrima is consistent with the literature data on the nutrient requirements of these microorganisms (Smith \& Divol 2016; Canonico et al. 2017; Barbosa et al. 2018; Bellut \& Arendt 2019).

\section{Colour}

Beer colour is predominantly dependent on the compounds resulting from the Maillard reaction, to a smaller degree on products of polyphenol oxidation derived from malt and hops and, partially, from the caramelisation process. It is believed that colour compounds naturally occurring in brewing materials e.g. anthocyanins, flavonoids and carotenoids do not have a significant influence on the colour of the finished product (Daniels 1998). Changes in the colour of wort to its lighter colour during fermentation, are connected with the absorption of colour substances on the yeast cell surface, their reaction and the structural change of some chemical compounds, caused by a drop in pH (Matz 1991). The unfermented wort was characterised by the light colour of 9.5 EBC. After the fermentation process in each of the analysed samples it brightened, fitting within the range of 5.63 to $8.36 \mathrm{EBC}$ (Figure 8). Variants with S. cerevisiae and $W$. anomalus showed the lowest decrease of all samples without enzymes. A greater decrease was reported for B. bruxellensis and T. delbrueckii, and the greatest for $M$. pulcherrima. The dependencies were similar for batches with added Attenuzyme core, except for a significant change in the sample inoculated with $S$. cerevisiae, where a reduction of EBC was the highest). In batches fermented with Fungamyl BrewQ addition, dependencies were again different. The lowest drop in the EBC was reported for $M$. pulcherrima. A brighter colour appeared in the $W$. anomalus, $S$. cerevisiae and $T$. delbrueckii variants. The sample inoculated with $B$. bruxellensis had the largest decrease of the EBC colour (Figure 8).

The results suggest that the yeast used for experiment had a major impact on the colour of the beer, leading to the production of lighter-coloured beers. B. bruxellensis, T. delbrueckii and $M$. pulcherrima strains caused a larger decrease of colour than S. cerevisiae in samples without added enzymes (Figure 8). This may be related to the microbial enzyme activity of individual cultures, which may facilitate the decomposition of colour compounds of the wort. Changes in colour do not correspond to the differentiation of acidity and, therefore, one may assume that they are caused by enzymatic activity and different metabolic activity of microorganisms in the tested environments. Results showed that the analysed nonSaccharomyces yeast species did not have a negative impact on the beer colour.

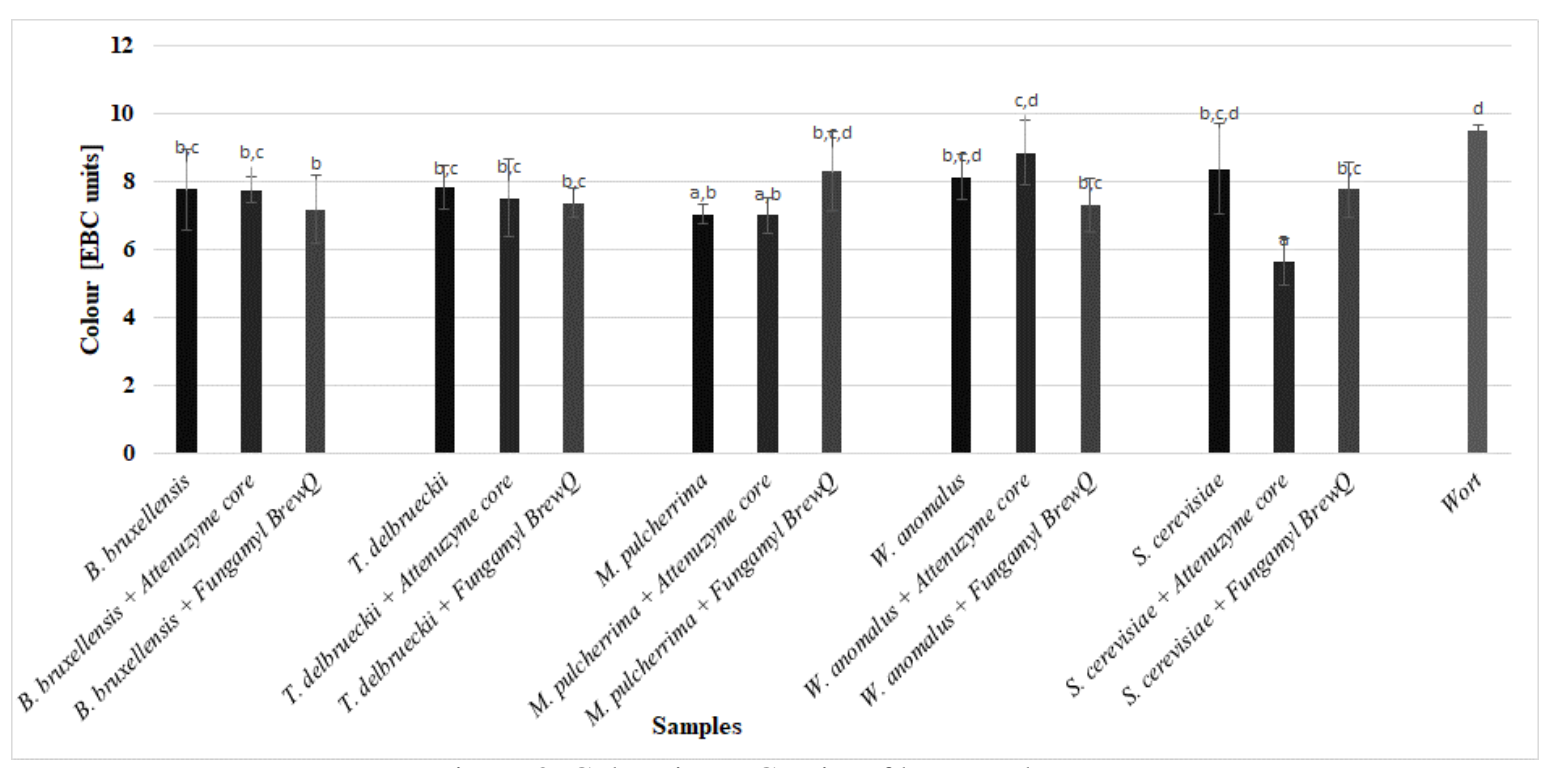

Figure 8. Colour in EBC units of beers and wort 


\section{Sugar content}

Neither fructose nor saccharose was found in the analysed wort (Table 1). Typical brewing wort contains small quantities of these sugars (Table 1). Their absence is likely to be related to the parameters of the malt used. They also weren't present in beers, even in trace amounts. The wort used for the experiments had a glucose concentration below typical ones (Table 1). All fermented samples without any added enzymes, except for the variant inoculated with $T$. delbrueckii, were characterised by a similar, low level of residual glucose (Table 1). The concentration of the sugar in the beer inoculated with $T$. delbrueckii was several times higher than in other samples (Table 1).

Beer inoculated with $B$. bruxellensis with Fungamyl BrewQ application was characterised by the highest, nearly double level of residual glucose as compared to other tests (Table 1). The results suggested that, depending on the composition of the medium, carbohydrates are assimilated differently by the tested yeasts. For all yeast except for T. delbrueckii, increase in maltose concentration resulted in the reduced consumption of glucose, as shown in the samples where the maltose-producing enzyme Fungamyl BrewQ was applied. The conclusion is confirmed in the literature for S. cerevisiae (Ernandes et al. 1993). The effect occurring in the analysed species leads to assumptions that they are well adapted to maltose assimilation. The analysed wort contains low maltose level (Table 1). The highest content of maltose residues was found in samples fermented with $S$. cerevisiae and $W$. anomalus without enzyme addition as well as in samples with added Attenuzyme Core enzyme (Table 1). Again, the dependencies were significantly different for samples with Fungamyl BrewQ enzyme. The highest maltose concentration was found in beers fermented with $T$. delbrueckii and $W$. anomalus. The lowest concentration of maltose remained in beer fermented with $B$. bruxellensis. The results showed that the non-Saccharomyces yeast tested consumes maltose to an extent similar to $S$. cerevisiae (Table 1). This confirms the positive adaptation of the tested microorganisms to the assimilation of this sugar.

Glycerol is the third most abundant product of the fermentative yeast metabolism after ethanol and carbon dioxide. This compound features a characteristic sweet flavour and, to a large extent, is responsible for the full flavouring of fermented beverages. It also enhances the perception of taste, reduces perceptible roughness during consumption, and affects the retention of volatile aromatic substances. Its standard content in beers ranges from 1 to $3 \mathrm{~g} / \mathrm{L}$ (Eßlinger 2009; Zhao et al. 2015). The main reasons for microorganisms to produce glycerol are its protective properties against osmotic and thermal stresses (Klein et al. 2017). As glycerol is a by-product of the yeast metabolism, it was not found in wort (Table 1). Its content varied in analysed beers (Table 1). All the beers inoculated with non-Saccharomyces yeast, without enzymes, were characterized by higher glycerol concentration than that of the control sample (Table 1), with the variant inoculated with $T$. delbrueckii containing the highest amount. These dependencies were similar in beers with added Attenuzyme Core enzyme. Again, all the tested non-Saccharomyces species produced more glycerol than $S$. cerevisiae.

Table 1. Glucose, maltose and glycerol content in wort and beers.

\begin{tabular}{|c|c|c|c|}
\hline Samples & Glicerol [g/L] & Glucose $[\mathrm{g} / \mathrm{L}]$ & Maltose [g/L] \\
\hline B. bruxellensis & $1.693^{b, c, d}( \pm 0.155)$ & $0.163^{\mathrm{d}}( \pm 0.082)$ & $0.434^{\mathrm{f}, \mathrm{g}}( \pm 0.005)$ \\
\hline B. bruxellensis + Attenuzyme Core & $2.659^{\mathrm{f}, \mathrm{g}}( \pm 0.179)$ & $0.343^{\mathrm{d}}( \pm 0.008)$ & $1.601^{\mathrm{b}, \mathrm{c}}( \pm 0.486)$ \\
\hline B. bruxellensis + Fungamyl BrewQ & $2.441^{\mathrm{f}}( \pm 0.014)$ & $4.011^{\mathrm{b}}( \pm 0.062)$ & $0.239^{\mathrm{g}}( \pm 0.060)$ \\
\hline T. delbrueckii & $2.009^{\mathrm{d}, \mathrm{e}}( \pm 0.132)$ & $1.774^{\mathrm{c}}( \pm 0.271)$ & $0.975^{\mathrm{d}, \mathrm{e}, \mathrm{f}}( \pm 0.066)$ \\
\hline T. delbrueckii + Attenuzyme Core & $2.841^{\mathrm{g}}( \pm 0.171)$ & $0.989^{\mathrm{d}}( \pm 0.025)$ & $1.876^{\mathrm{b}}( \pm 0.017)$ \\
\hline T. delbrueckii + Fungamyl BrewQ & $2.848^{\mathrm{g}}( \pm 0.498)$ & $0.659^{\mathrm{d}}( \pm 0.024)$ & $1.045^{\mathrm{c}, \mathrm{d}, \mathrm{e}}( \pm 0.070)$ \\
\hline M. pulcherrima & $1.582^{\mathrm{b}}( \pm 0.198)$ & $0.106^{\mathrm{d}}( \pm 0.083)$ & $0.972^{\mathrm{d}, \mathrm{e}, \mathrm{f}}( \pm 0.032)$ \\
\hline M. pulcherrima + Attenuzyme Core & $2.806^{\mathrm{g}}( \pm 0.161)$ & $0.000^{\mathrm{d}}( \pm 0.000)$ & $1.542^{\mathrm{b}, c, \mathrm{~d}}( \pm 0.331)$ \\
\hline M. pulcherrima + Fungamyl BrewQ & $2.107^{\mathrm{e}}( \pm 0.181)$ & $2.021^{\mathrm{c}}( \pm 0.008)$ & $0.667^{\mathrm{e}, \mathrm{f,g} g}( \pm 0.006)$ \\
\hline W. anomalus & $1.578^{\mathrm{b}}( \pm 0.128)$ & $0.000^{\mathrm{d}}( \pm 0.000)$ & $1.407^{\mathrm{b}, c, \mathrm{~d}}( \pm 0.429)$ \\
\hline W. anomalus + Attenuzyme Core & $2.551^{\mathrm{f,g}}( \pm 0.275)$ & $0.000^{\mathrm{d}}( \pm 0.000)$ & $1.508^{\mathrm{b}, c, d}( \pm 0.920)$ \\
\hline W. anomalus + Fungamyl BrewQ & $1.781^{\mathrm{b}, \mathrm{c}, \mathrm{d}, \mathrm{e}}( \pm 0.047)$ & $1.888^{\mathrm{c}}( \pm 0.025)$ & $1.088^{\mathrm{c}, \mathrm{d}, \mathrm{e}}( \pm 0.284)$ \\
\hline S. cerevisiae & $1.163^{\mathrm{b}, \mathrm{c}}( \pm 0.199)$ & $0.000^{\mathrm{d}}( \pm 0.000)$ & $1.379^{\mathrm{b}, c, \mathrm{~d}}( \pm 0.255)$ \\
\hline S. cerevisiae + Attenuzyme Core & $2.453^{\mathrm{f}}( \pm 0.097)$ & $0.000^{\mathrm{d}}( \pm 0.000)$ & $1.480^{\mathrm{b}, \mathrm{c}, \mathrm{d}}( \pm 0.049)$ \\
\hline S. cerevisiae + Fungamyl BrewQ & $1.976^{\mathrm{c}, \mathrm{d}, \mathrm{e}}( \pm 0.082)$ & $1.968^{\mathrm{c}}( \pm 0.105)$ & $0.807^{\mathrm{e}, \mathrm{f}}( \pm 0.329)$ \\
\hline Wort & $0.000^{\mathrm{a}}( \pm 0.000)$ & $6.315^{\mathrm{a}}( \pm 0.214)$ & $28.803^{\mathrm{a}}( \pm 0.195)$ \\
\hline
\end{tabular}


In the samples to which Fungamyl BrewQ enzyme was applied, glycerol content was most differentiated. T. delbrueckii again produced the highest volume of glycerol (Table 1). The analysed non-Saccharomyces yeast species produce more glycerol than traditionally used brewing yeast. This phenomenon has already been demonstrated in other works (Contreras et al. 2014).

\section{Volatile compounds}

During the alcohol fermentation process, brewing yeasts, apart from ethanol and carbon dioxide, synthesise a wide spectrum of metabolites, the majority of which affect the organoleptic properties of the resulting beer. These compounds lend it a specific and characteristic taste and aroma.

One of the main groups of compounds synthesised by yeast are higher alcohols (fusels). In spite of their negative impact on the taste and aroma of beer, they may be of importance due to their participation in the production of esters (Younis \& Stewart 1998). They lend a plastic, solvent-like flavour and aroma to beer. Higher alcohols are formed during the main fermentation and their content is basically dependent on three factors: yeast strain, wort composition and process parameters. It is believed that non-Saccharomyces yeast is responsible for creating low concentrations of higher alcohols (n-propanol, isobutanol, amyl alcohols) in relation to $S$. cerevisiae cultures (Romano \& Suzzi 1993; Zironi et al. 1993). This has not been shown in our research. The obtained beer was characterised by a considerably richer aroma than traditionally fermented beers with the participation of $S$. cerevisiae. Particular attention should be paid to the B. bruxellensis strain. It synthesised significantly higher amounts of 1hexanol, 2.3-butanediol, 1-octanol, 2-methyl-1propanol while the amount of 1-nonanol and 2ethyl-1-hexanol were comparable (Table 2-3). B. bruxellensis has been known as one of the bestanalysed non-Saccharomyces yeasts. The specific aroma of beer produced with $B$. bruxellensis may contribute to their more common application in subsequent years. Particular attention should be paid to their potential application in increasingly popular, highly attenuated beers (Michel et al. 2016). In most cases, the use of Fungamyl BrewQ affected the higher concentration of the volatile compounds in the finished beverage analysed in the research (Table 3). This phenomenon is understandable. The addition of an enzyme affected the decomposition of polysaccharides to the maltose used by yeast. Note that some components present in beer (3-ethoxy-1-propanol) were not confirmed in samples without the enzyme (Table 3). Since M. pulcherrima strains have the capability of assimilating glucose and maltose, etc., the addition of enzymes had an impact on the significant increase of higher alcohols content in the finished product (Table 2-3). Furthermore, the representatives of this species also produces extracellular hydrolytic enzymes such as pectinasis, proteases, $\beta$-glucosidases, $\beta$-glucanases, cellulases, cellobiases and amylases. Thanks to these enzymatic activities, $M$. pulcherrima used for fermentation may release the volatile compounds glycosidially bonded and, to $\beta$-lyases, release volatile thiols from cysteine precursors (Contreras et al. 2014).

Esters represent the largest group of side products occurring in fermented beverages (Verstrepen et al. 2003; Procopio et al. 2011). Aside from the possibility of their formation from the chemical condensation of acids and alcohols, the majority of them are a product of the yeast metabolism. The enzymatic synthesis of esters is catalysed by a series of enzymes (esterases, lipases) produced by microbes, including acetyltransferase. Alcohol and acetylocoenzyme A are the substrates of the reaction. Although approximately 60 different esters were discovered in beer, only a few of them play an important role in aroma formation. In their majority, Saccharomyces yeast synthesises ethyl and acetate esters. One of them is ethyl acetate. The analysis showed the lowest content of the component in beers produced with $S$. cerevisiae. Non-Saccharomyces strains synthesised much higher levels of these compounds (Tables 2-3). The highest levels of esters were reported for beers obtained with the participation of $T$. delbrueckii and $W$. anomalus (Table 2). The aroma of beers fermented with $T$. delbrueckii is described as being high in esters, full-bodied and fruity. These yeast seem particularly interesting in the production of beverages with reduced alcohol content and with exceptional sensory properties, especially with floral aroma (King \& Richard Dickinson 2000; Canonico et al. 2016; Michel et al. 2016). A significantly lower content of ethyl esters, as compared to $T$. delbrueckii, was observed in the case of B. bruxellensis (Tables 2-3). While these strains are capable of synthesising high quantities of ethyl esters such as ethyl acetate, ethyl lactate, ethyl decanoate and ethyl octanoate, their quantity in beers was insignificant when compared to other non-Saccharomyces yeast. 


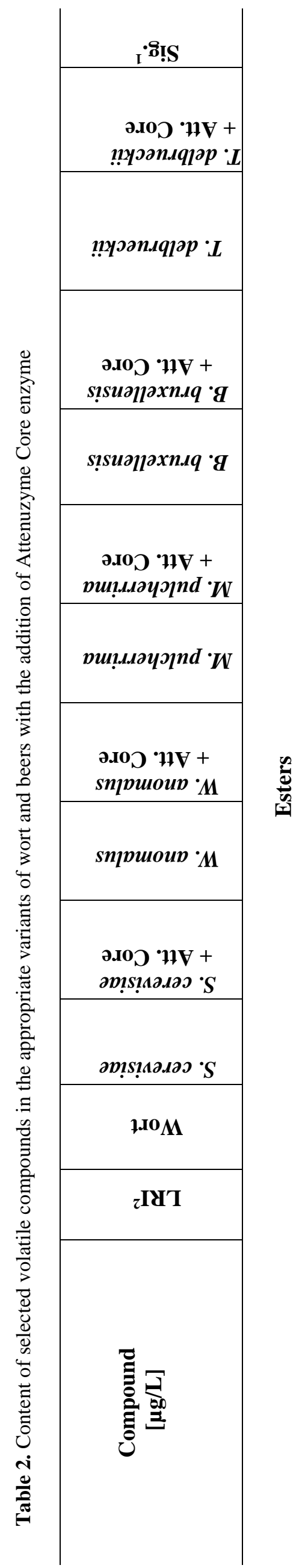

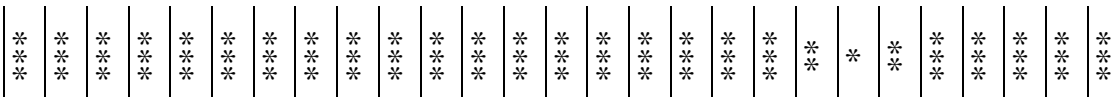

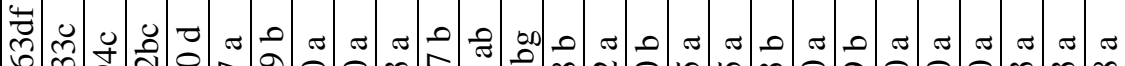

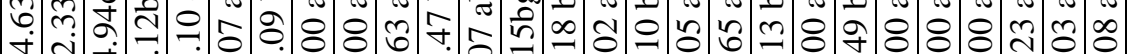

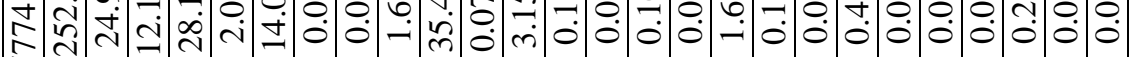

గุ:

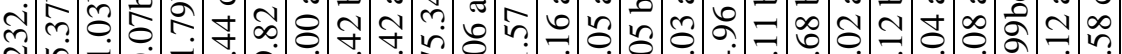

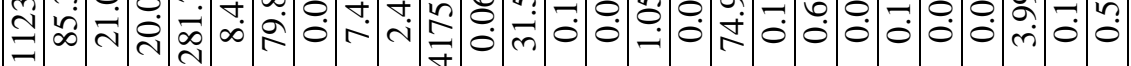

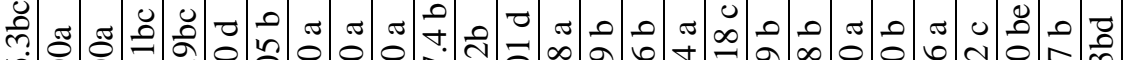
饣.

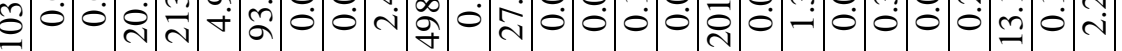

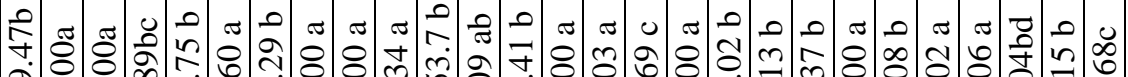
¿ों ஸे

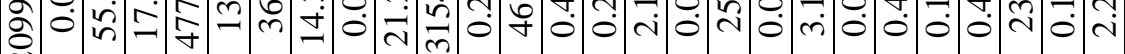

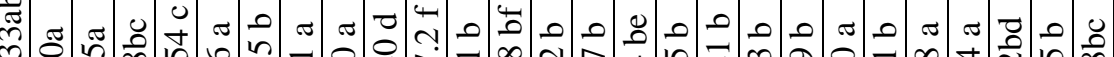
m. ही مी

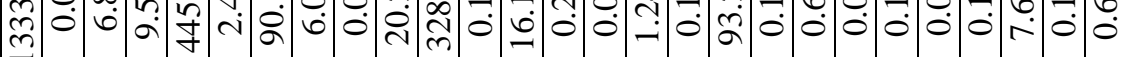

20

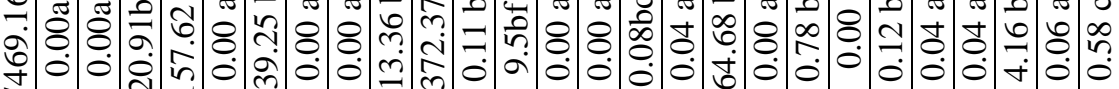

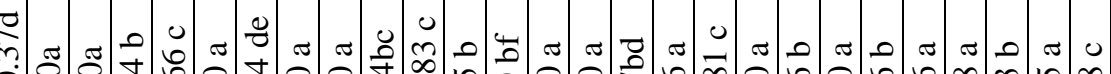
官

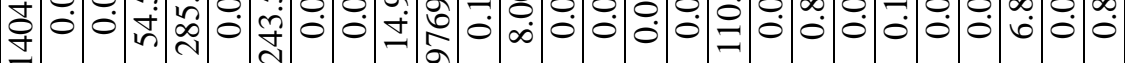

ஸి

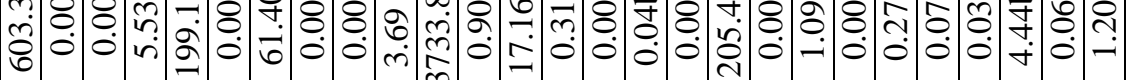

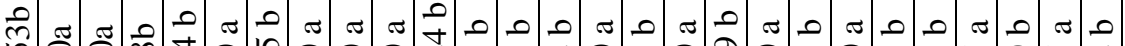
กิ \&

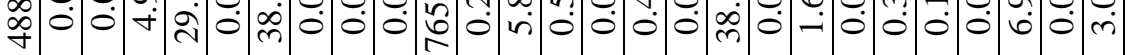

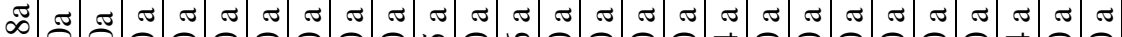

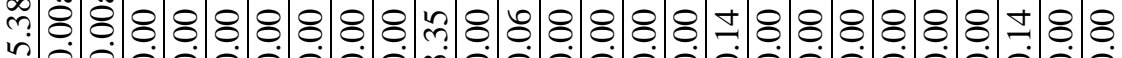

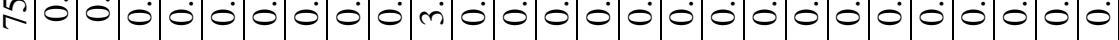

ఫ)

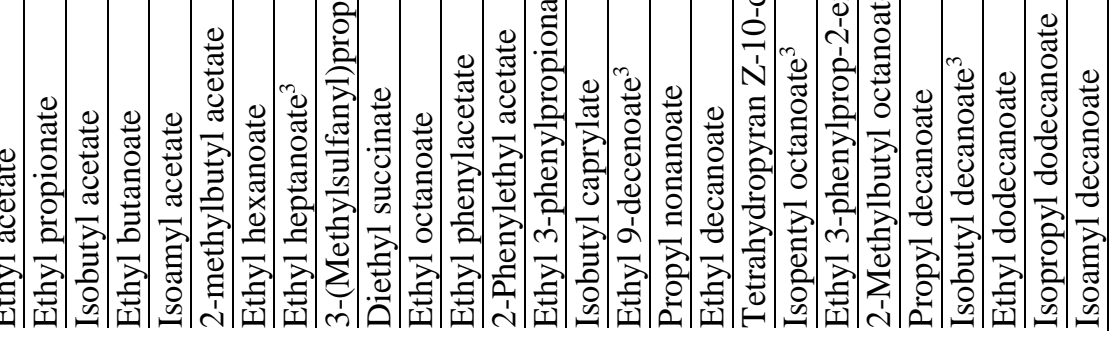




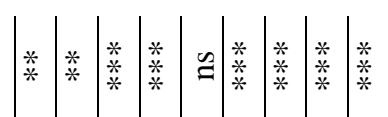

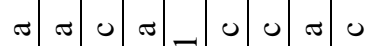

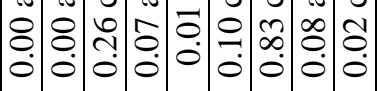

\begin{tabular}{lllll|llll}
$\pi$ & $\pi$ & 0 & $\pi$ & $n$ & 0 & 0 & 0 & $\pi$
\end{tabular}

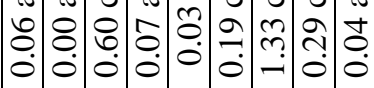

$\begin{array}{lllllllll}0 & \pi & 0 & \pi & n & 0 & 0 & 0 & \pi\end{array}$

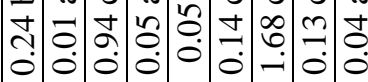

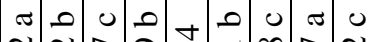

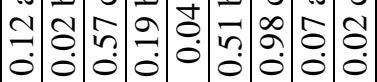

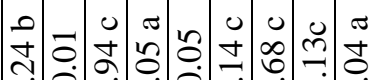

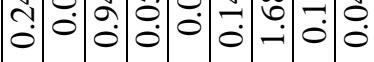

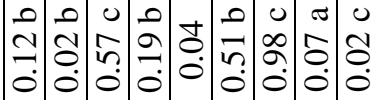

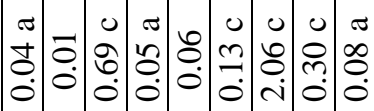

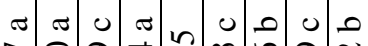

50

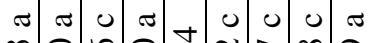

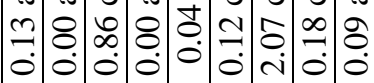

م

กิ

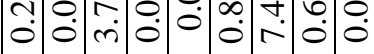

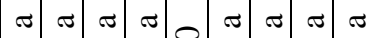

ஓு

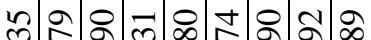

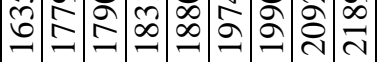

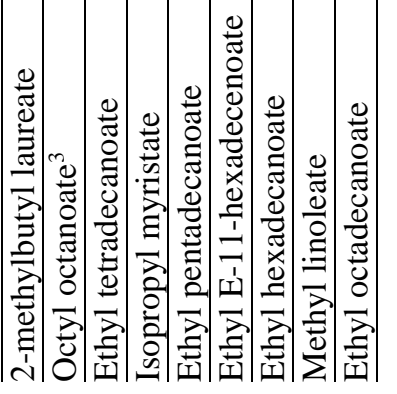

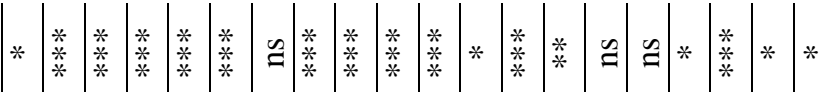

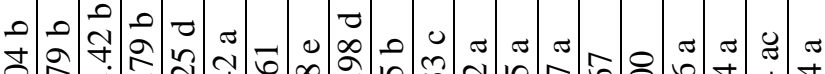

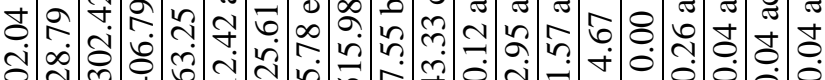
ঠิ ป̂

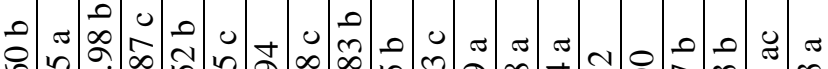

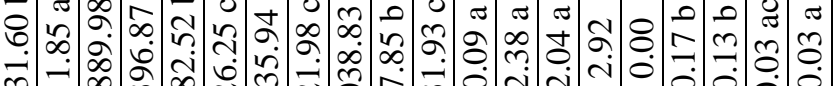

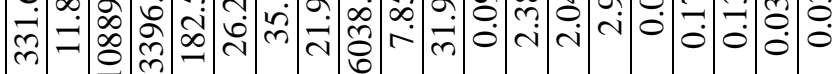

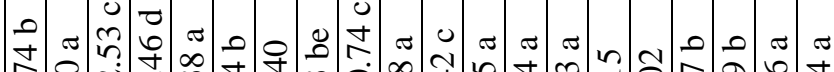

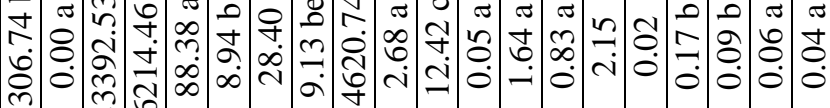

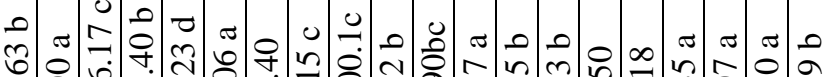
అิ ๙ คิ

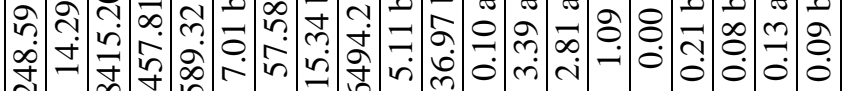

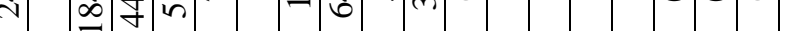

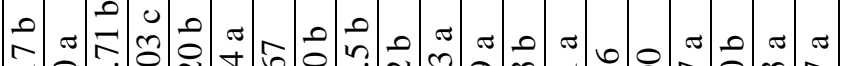

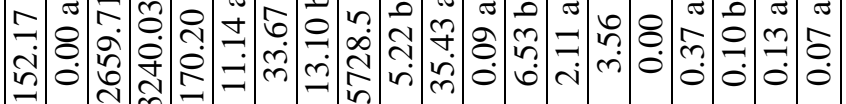

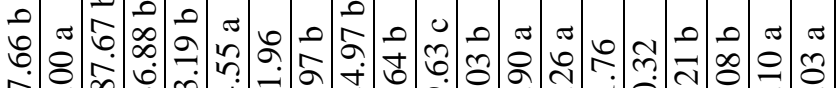
I

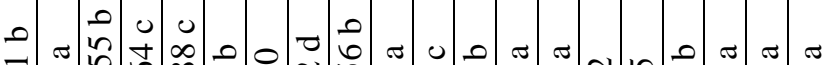

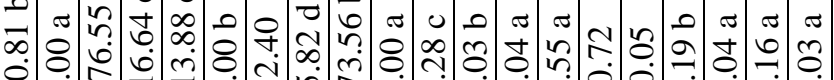

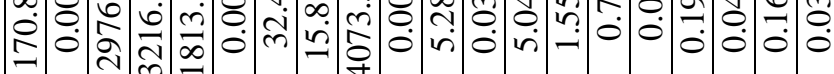

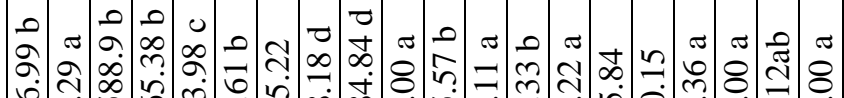

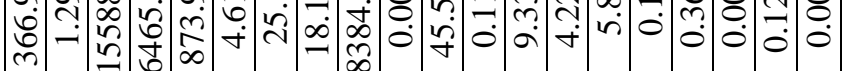
م

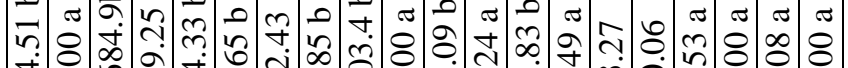
年

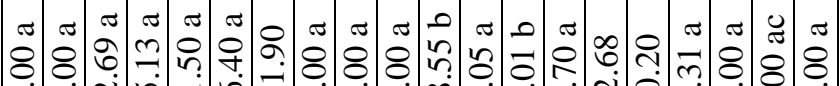
官

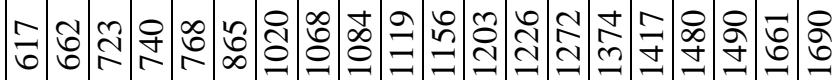

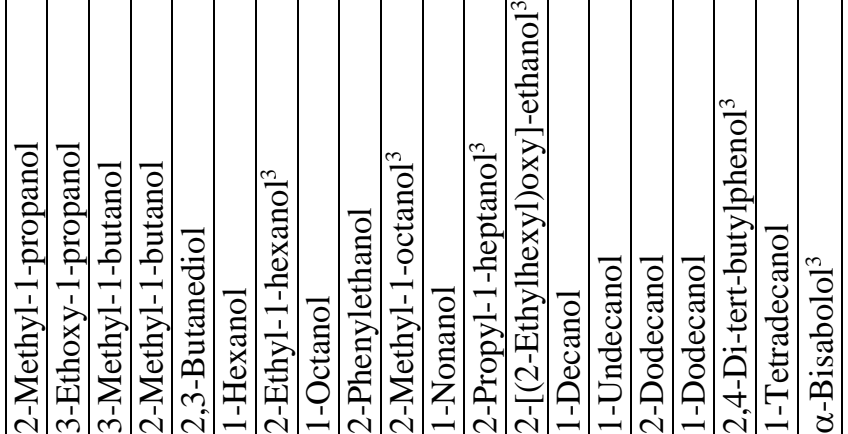

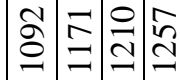

$\cong \because \frac{*}{*}=$

م)

심ำ

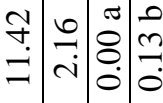

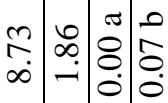

œ 기잉

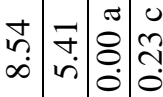

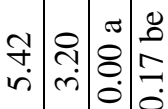

은

기

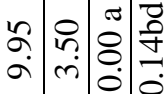

ก ชู

$\infty$ त

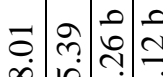

$\infty$ in

+ $-\pi$

$\infty$

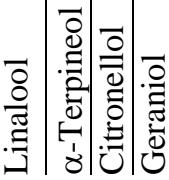




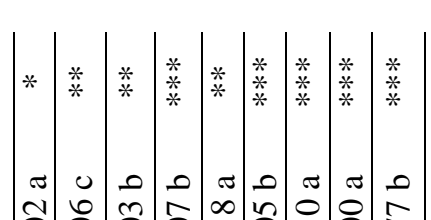

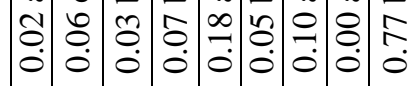

.

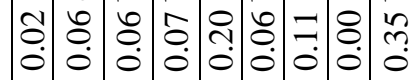

$\ldots=\ldots$

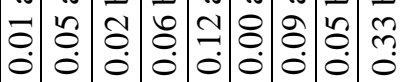

$\ldots$

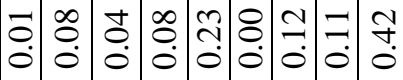

……

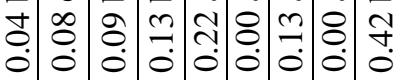

S $A=1$

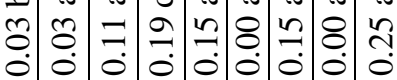

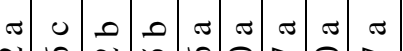

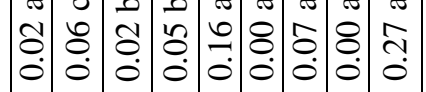

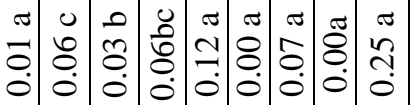

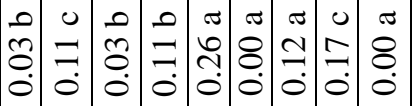

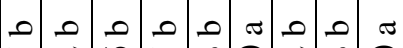

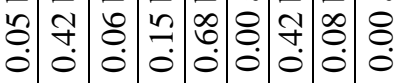

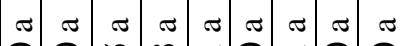

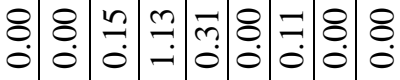

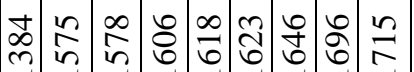

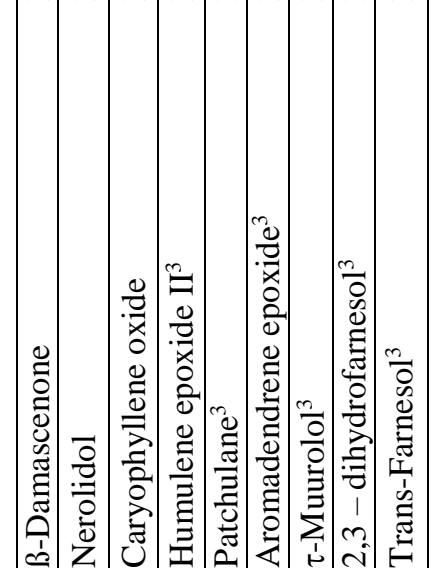

$\mid$

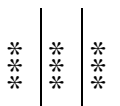

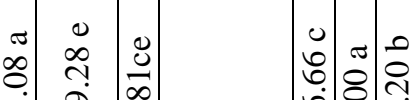

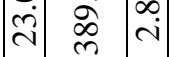

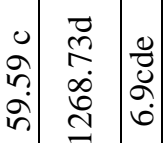

ค.

ล. 守

$\stackrel{\infty}{\mathrm{N}} \approx$

$\stackrel{\mathscr{\varrho}}{\Xi}$

일

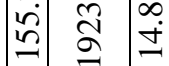

ㅇํㅇำ

î.

$\approx 2 \infty \quad$

-. 0 范

辛

กิ:

م 10.

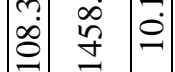

0 ०

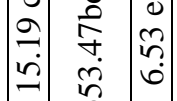

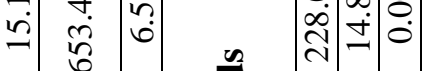

-

它

递

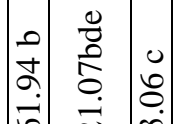

चे

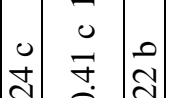

लె.

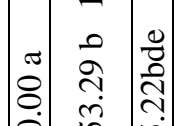

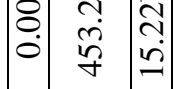

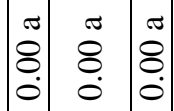

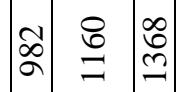

? 2

芒过

ल 0 ०

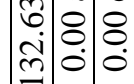

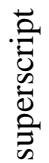

产

节

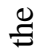

눙

퐁

.

$\Xi$

is

䨌

穵

$\stackrel{5}{ \pm}$

잉

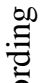

ర্

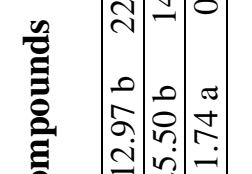

ㄱํ

市苞 है

- $\circ$.

ஸ̂.

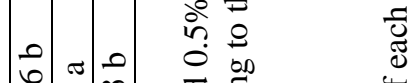

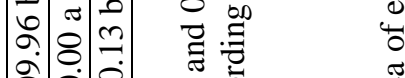

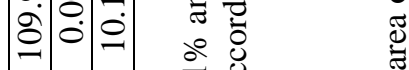

ते จ

$m 0 \dot{0}=$

:

요료

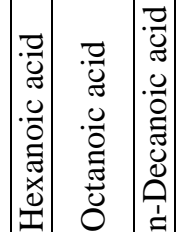

ले

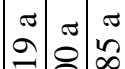

$\stackrel{2}{2}$

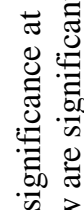

की

के 3

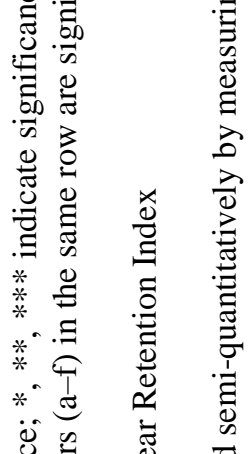

D

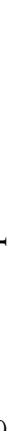

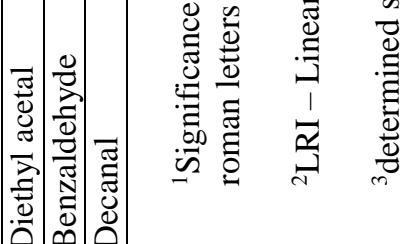




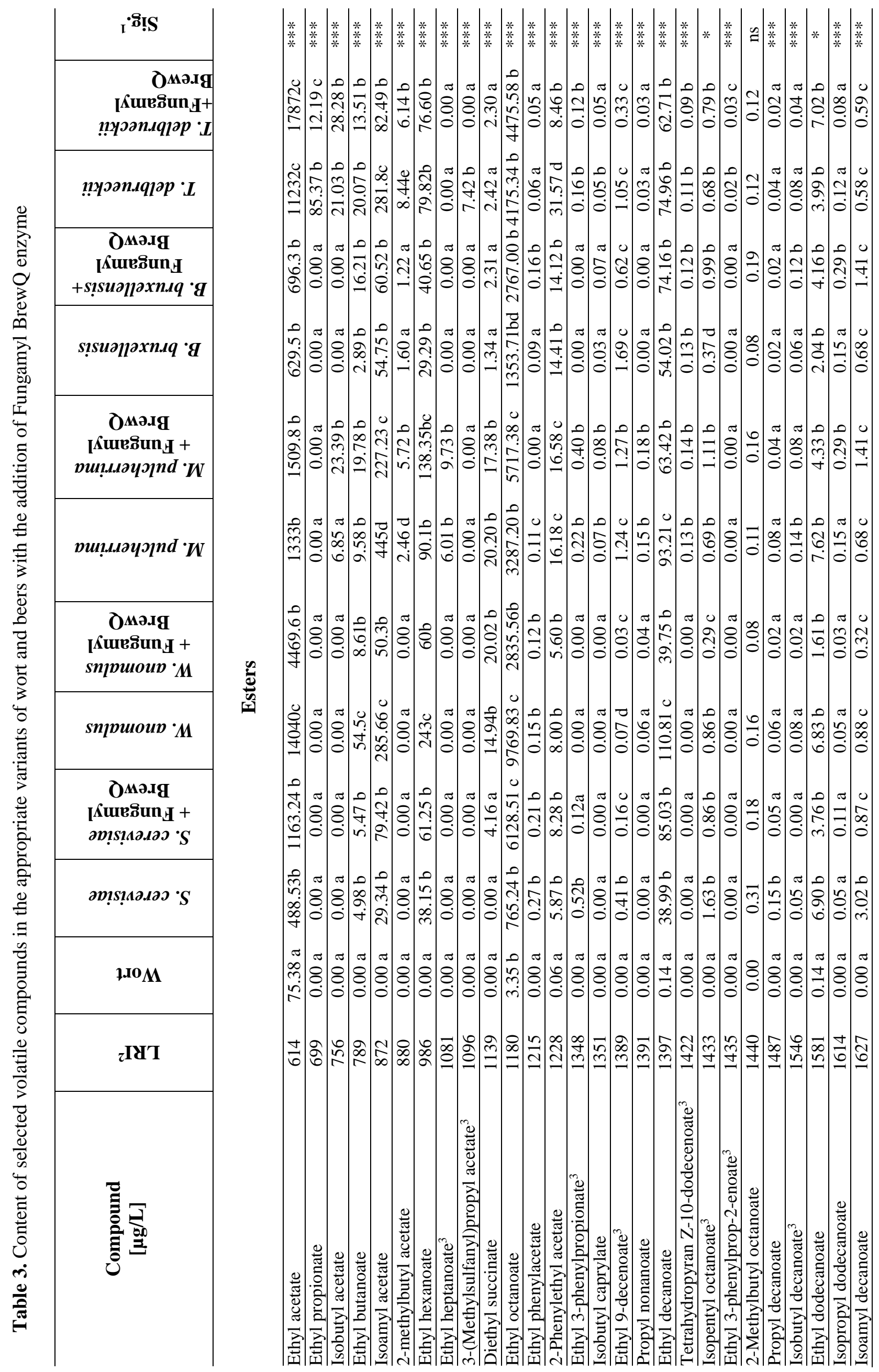




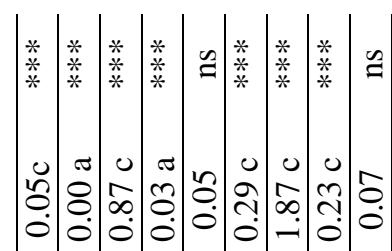

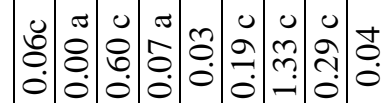

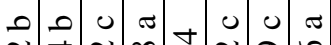

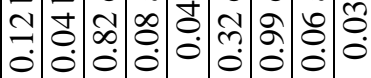

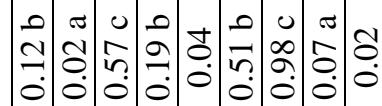

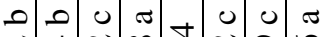

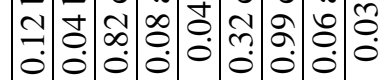

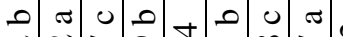

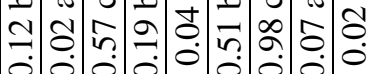

$\begin{array}{llllllll}0 & \pi & 0 & \pi & 0 & 0 & 0 & 0\end{array}$

○.

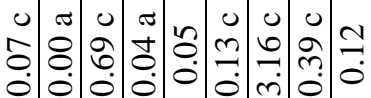

- 0 0 0 - 0 0 0

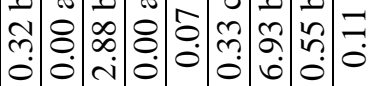

- 0 م

กิ

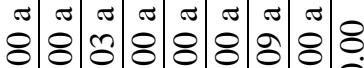

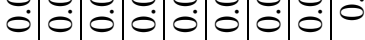

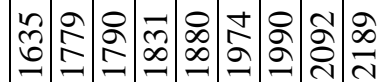

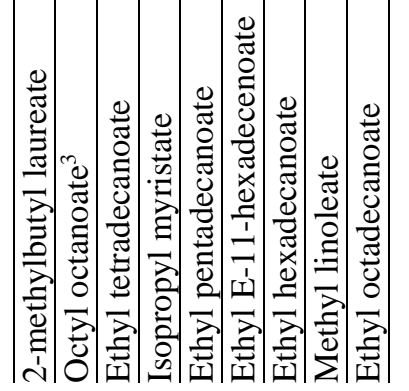

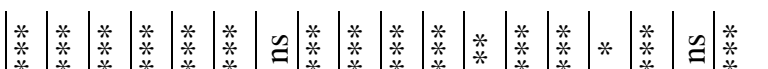

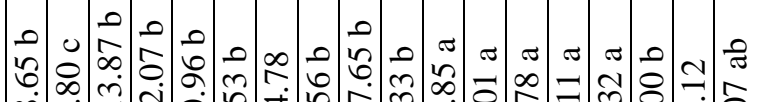

m

$\stackrel{m}{m} \mid$\begin{tabular}{l}
0 \\
\hdashline
\end{tabular}

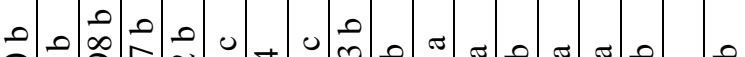

b.

m)

mệ.

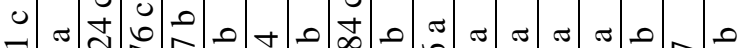

$\infty$ ஓ

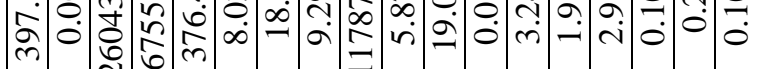

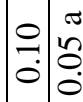

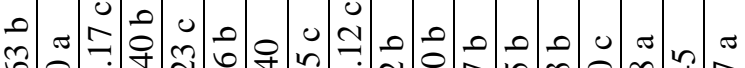

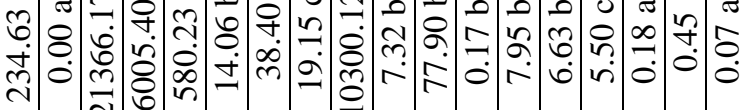

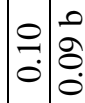

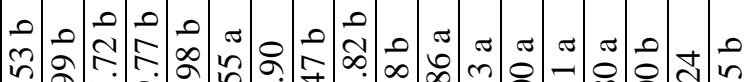

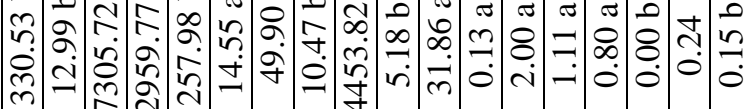

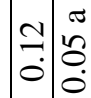

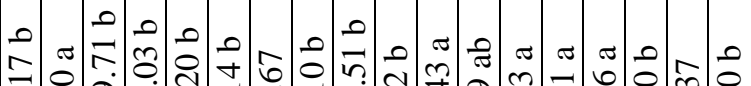

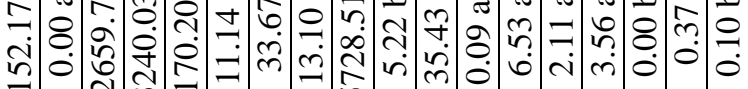

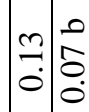

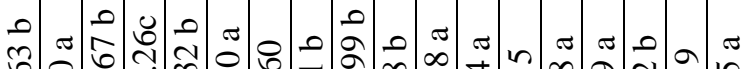

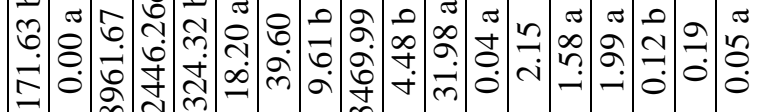

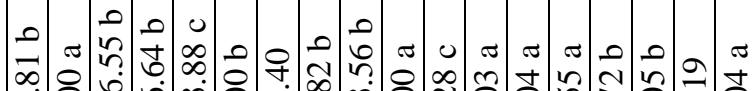

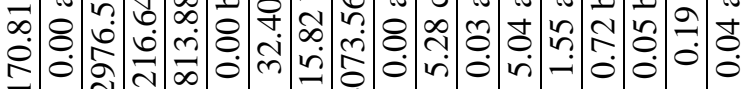

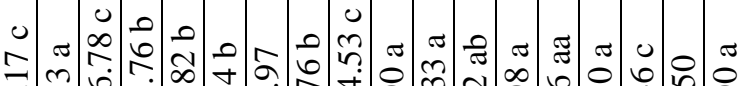

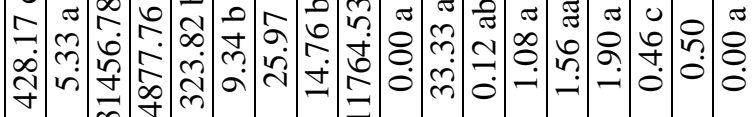

Иี

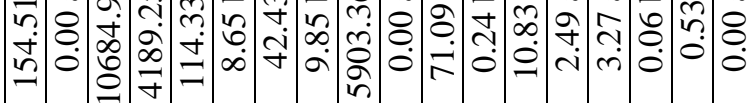

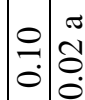

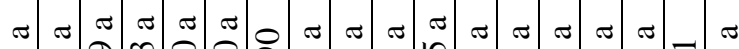

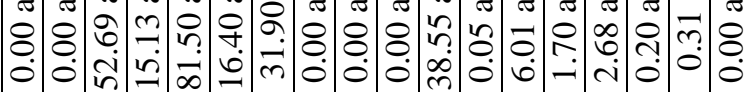

:

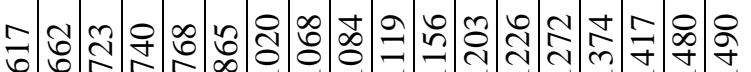

중

\begin{tabular}{ccc}
0 & 0 \\
\hdashline & 0 & 0 \\
0 & 0 \\
0 & 0
\end{tabular}

กิ่

$\stackrel{\pi}{8}$

$\div: 0$.

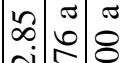

기숭

กิ

$=-\dot{0}$

ㄴำ

vं. ஸே

0

๙ิ

mo

!

a mi

$\infty$

ஸ்

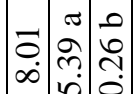

赵

$\sim i$ i

의츠을

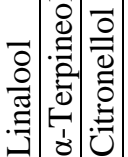




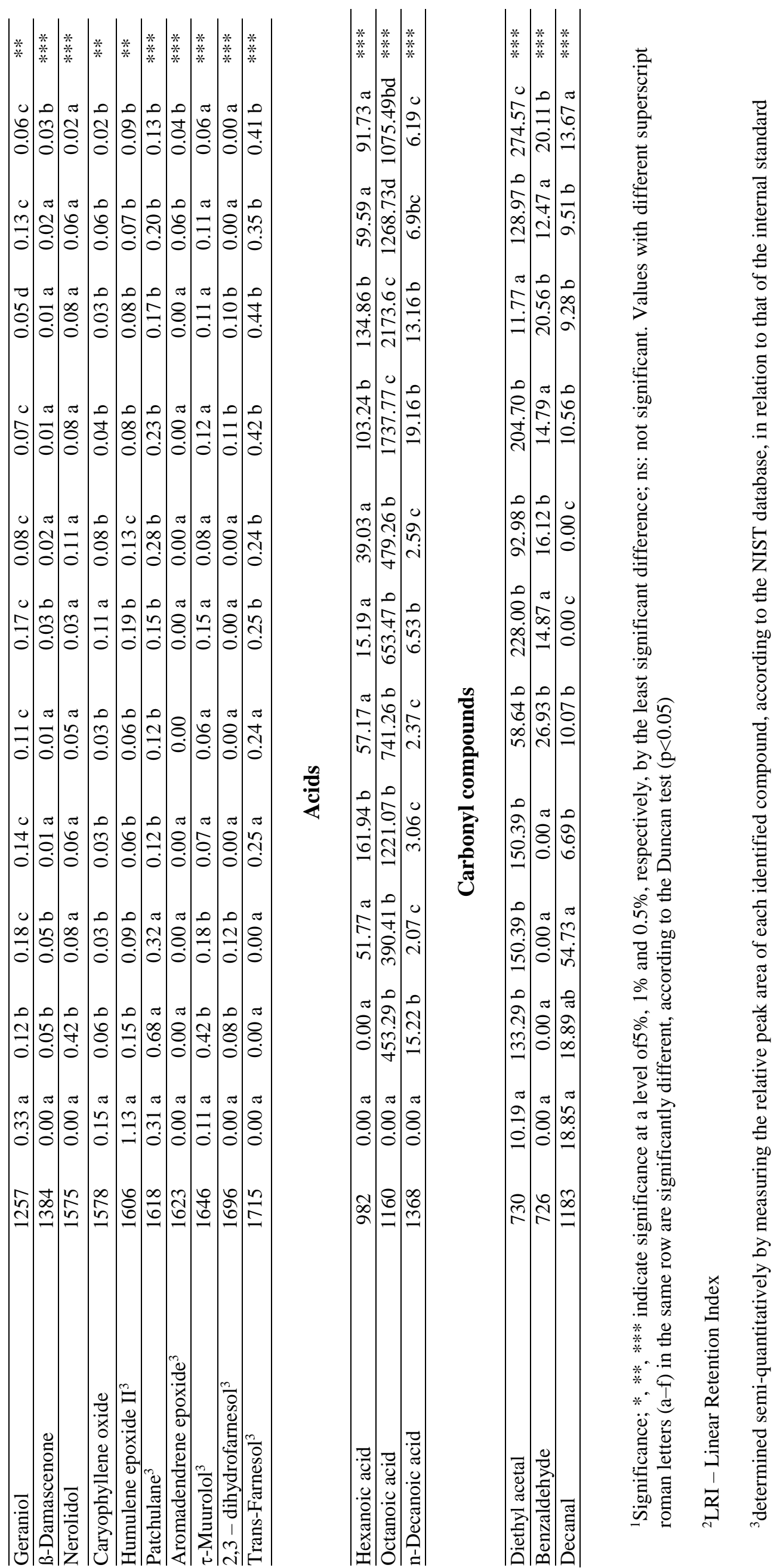


Ethyl decanoate and ethyl octanoate are considered typical Lambic and Gueuze beer aromas, which contributes their characteristic fruity and wineflavoured aroma. It is interesting that beers produced with $M$. pulcherrima contained a higher concentration of acetates compared to samples fermented with $B$. bruxellensis. The $M$. pulcherrima strains has not yet been widely tested. The majority of publications devoted to this yeast focus on wine fermentation by using mixed Saccharomyces and non-Saccharomyces cultures. However, it is suggested by available data that some specific strains may be used to produce beer with reduced alcohol content. Sugar oxidation capacity without alcohol production and a wide range of enzymatic activities suggest the need for further research with the species (Varela \& Borneman 2017). A high content of ethyl esters was found in beers obtained with $W$. anomalus (Tables 2-3). The test results are consistent with the data available in literature. An overly high level of ethyl acetate is considered undesirable in beers, and may contribute a solvent-like aroma to beer. $W$. anomalus produces relatively high levels of ethyl butyrate, 1-phenylethanol and 2phenylethanol acetate (Padilla et al. 2018). Similarly as for higher alcohols, in most cases, the level of esters in beers increased when enzymes were added (Table 3). On the other hand, the lower content of volatile compounds in beers with added enzymes could be caused by a higher share fusels in samples. It is assumed that conditions supporting the production of higher alcohols also cause a reduction in the ester content (Younis \& Stewart 1998; Campbell 2001).

The content of terpenes in alcoholic beverages is strictly dependent on the type and quality of raw material, as well as on the yeast strain used for fermentation (Muffler et al. 2011). These compounds are the key components of hops essential oils and are responsible for the characteristic "hoppy" beer flavour. It has been proven that $\beta$-myrcene, $\alpha$-humulene, $\beta$ caryophyllene and $\beta$-farnesene are the main components of hops oil. However, the finished beer is clearly dominated by terpene alcohols. $T$. delbrueckii yeast demonstrates monoterpenoid biotransformation capacity and, as one of very few, the ability to synthesise them. They are characterised by a flowery aroma and compounds from the group, such as geraniol and linalool, occur both in hops and in beer. T. delbrueckii may transform geraniol as well as other compounds in the wort to $\alpha$-terpineol, the component with pine and citrus aroma (King \& Richard Dickinson 2000; Canonico et al. 2016; Michel et al. 2016). The analysed beers were characterised by a relatively high content of mentioned components, including linalool, which occurred in higher concentrations in samples fermented with $T$. delbrueckii and $B$. bruxellensis (Tables 2-3). The unfermented wort was clearly dominated by geraniol, humulene epoxide II and patchulane, while the level of these components decreased after fermentation. Contrary to Saccharomyces yeast, the very high activity of $\beta$-glucosidases, which may release volatile compounds bonded with glycoside, e.g. terpenes from hops and other components added to wort (fruits or herbs), is demonstrated by the Brettanomyces strains (Yeo \& Liu 2014; Basso et al. 2016; Domizio et al. 2016; Callejo et al. 2017). In worts fermented with $B$. bruxellensis linalool, $\alpha$ terpineol, patchulane and trans-farnesole were found (Tables 2-3). In most cases, enzymes addition reduced the concentration of terpenes in beers (Tables 2-3).

Fatty acids in beer are differentiated by their aliphatic chain length. Short-chain fatty acids are highly undesirable as beer components. Their presence in the product is caused by damage to the cellular wall in response to ethanol stress and other factors and, in particular cases, as a result of cellular death and autolysis. The short- and medium-chained acids influence also the unpleasant aroma of a beverage and have an adverse effect on foam stability. (Briggs et al. 2004). The final concentration of the mediumlength chain in beer is strictly related to yeast activity and mainly dependent on its concentration inside a cell. In the analysed beers, the fatty acid content decreased in samples with enzymes addition. Octanoic acid was an exception (Tables 2-3). Non-Saccharomyces yeasts synthesised a significantly larger quantity of this compound compared to $S$. cerevisiae.

Aldehydes are among the key groups of compounds influencing beer quality. During beer wort fermentation, the components have a significant role to play in the sensory properties of beer and its flavour stability. Similarly to other carbonyl compounds, aldehydes have a negative impact on the properties of the beverage due to their low sensory detection thresholds and high reactivity (Vanderhaegen et al. 2007). In the analysed beers, a small quantity of carbonyl compounds was found. A low content of benzaldehyde and decanal was found in beers produced with $T$. delbrueckii (Tables 2-3). The strain does not decarboxylate hydroxycinammic acids and is characterised by allow production of compounds, such as acids and aldehydes, not particularly desire in beer production. 


\section{Metal ions}

Metal ions are among the important factors influencing the fermentation process and quality of beer. Of many elements, magnesium, zinc and calcium, are typically mentioned in relation to the brewing technology, as they perform many functions in the metabolism of yeast cells (Poreda et al. 2009). During the brewing process, special attention is paid to wort lautering, which contributes to the loss of the largest volume of ions. For this reason, each production stage is supervised by process engineers/brewers in order to track losses of elements, as insufficient content of zinc or magnesium may stop fermentation (Stehlik-Tomas et al. 2004). Magnesium was the first analysed element. Magnesium is required for the proper functioning of nearly 300 enzymes. As an element, it also has the highest occurrence and participation in many biochemical processes appearing in yeast cells (Birch \& Walker 2000). Brewing yeasts are characterised by the high demand for magnesium ions in wort $(50-150 \mathrm{mg} / \mathrm{L}$ or more) (Rees \& Stewart 1999). Ethanol yield during fermentation increases with the increase in $\mathrm{Mg}^{2+}$ ions concentration in a cell (Szigeti et al. 2005). Table 4 presents the results of magnesium content for pitching worts and finished beers. The concentration of magnesium in the pitching wort was $138.65 \mathrm{mg} / \mathrm{L}$ and this result is consistent with the data in the literature required for the proper fermentation process. In the final product, the highest magnesium content was observed in beers fermented by $T$. delbrueckii yeast with added Fungamyl BrewQ (93.25 mg/L) enzyme compared to the beer fermented with $T$. delbrueckii yeast. Zinc was another element analysed in the tests.
Zinc ions are a necessary nutrient component for yeasts. The principal source of zinc is malt, from which zinc is extracted in the mashing process (De Nicola \& Walker 2009). The optimum demand of yeast for zinc oscillates between $0.1-1 \mathrm{mg} / \mathrm{L}$ of wort (Poreda et al. 2015). Zinc content in the wort produced from barley malt was at the appropriate level $(0.63 \mathrm{mg} / \mathrm{L})$ required for the proper performance of yeast. After the fermentation process ended, beer brewed with $M$. pulcherrima yeast + Attenuzyme Core had higher zinc content $(0.7 \mathrm{mg} / \mathrm{L})$ compared to the beer fermented without the enzyme $(0.42 \mathrm{mg} / \mathrm{L})$. Also note $T$. delbrueckii yeast, which used a significantly larger content of zinc $(0.21 \mathrm{mg} / \mathrm{L})$ compared to other samples during the fermentation process.

The final tested element was calcium. It was proven that calcium also influences certain specific enzymatic reactions, facilitated synthesis of the cell material, and prevented its leaking, as well as allowing for the adjustment of the $\mathrm{pH}$ of wort (MacDiarmid et al. 2002). $\mathrm{Ca}^{2+}$ content appropriate for the proper growth of the yeast and for the fermentation process was determined ranging from 30 to $60 \mathrm{mg} / \mathrm{L}$ of wort (Wietstock et al. 2015). The calcium content in wort before launching the fermentation process was $48.49 \mathrm{mg} / \mathrm{L}$, which is consistent with literature. In the final product, i.e. beer, the content of this element was significantly reduced when compared to the initial sample and averaged at $25-30 \mathrm{mg} / \mathrm{L}$, which contributes to enhancing the taste impressions of the resulting beers (Evans et al. 2003). The highest consumption of calcium was observed in beers produced with M. pulcherrima yeast + Fungamyl BrewQ (21.29 $\mathrm{mg} / \mathrm{L})$.

Table 4. Content of selected ions in the appropriate variants of wort and beers.

\begin{tabular}{|l|c|c|c|}
\hline Variety of wort and beers & $\begin{array}{c}\text { Ca 422,7 } \\
{[\mathrm{mg} / \mathrm{L}]}\end{array}$ & $\begin{array}{c}\text { Zn 213,9 } \\
{[\mathrm{mg} / \mathrm{L}]}\end{array}$ & $\begin{array}{c}\text { Mg 202,6 } \\
{[\mathrm{mg} / \mathrm{L}]}\end{array}$ \\
\hline Wort & $48.49^{\mathrm{a}}( \pm 3.55)$ & $0.63^{\mathrm{a}}( \pm 0.04)$ & $138.65^{\mathrm{a}}( \pm 5.54)$ \\
\hline S. cerevisiae & $25.24^{\mathrm{b}}( \pm 5.38)$ & $0.43^{\mathrm{a}}( \pm 0.16)$ & $55.49^{\mathrm{b}}( \pm 17.7)$ \\
\hline W. anomalus & $32.27^{\mathrm{b}}( \pm 2.18)$ & $0.29^{\mathrm{a}}( \pm 0.1)$ & $66.3^{\mathrm{b}}( \pm 6.9)$ \\
\hline B. bruxellensis & $32.81^{\mathrm{b}}( \pm 1.32)$ & $0.24^{\mathrm{a}}( \pm 0.05)$ & $68.91^{\mathrm{b}}( \pm 4.74)$ \\
\hline M. pulcherrima & $27.82^{\mathrm{b}}( \pm 3.1)$ & $0.42^{\mathrm{a}}( \pm 0.21)$ & $58.88^{\mathrm{b}}( \pm 14.32)$ \\
\hline T. delbrueckii & $31.89^{\mathrm{b}}( \pm 3.39)$ & $0.21^{\mathrm{b}}( \pm 0.07)$ & $70.86^{\mathrm{b}}( \pm 3.74)$ \\
\hline S. cerevisiae + Attenuzyme Core & $29.28^{\mathrm{b}}( \pm 5.55)$ & $0.48^{\mathrm{a}}( \pm 0.08)$ & $63.35^{\mathrm{b}}( \pm 6.42)$ \\
\hline W. anomalus + Attenuzyme Core & $29.74^{\mathrm{b}}( \pm 2.85)$ & $0.43^{\mathrm{a}}( \pm 0.2)$ & $65.4^{\mathrm{b}}( \pm 7.94)$ \\
\hline B. bruxellensis + Attenuzyme Core & $29.76^{\mathrm{b}}( \pm 1.25)$ & $0.28^{\mathrm{a}}( \pm 0.03)$ & $68.45^{\mathrm{b}}( \pm 4.38)$ \\
\hline M. pulcherrima +Attenuzyme Core & $32.98^{\mathrm{b}}( \pm 3.42)$ & $0.7^{\mathrm{a}}( \pm 0.45)$ & $71.44^{\mathrm{b}}( \pm 8.34)$ \\
\hline T. delbrueckii + Attenuzyme Core & $32.26^{\mathrm{b}}( \pm 3.85)$ & $0.27^{\mathrm{a}}( \pm 0.19)$ & $70.72^{\mathrm{b}}( \pm 4.35)$ \\
\hline S. cerevisiae + Fungamyl BrewQ & $30.65^{\mathrm{b}}( \pm 1.96)$ & $0.34^{\mathrm{a}}( \pm 0.1)$ & $61.29^{\mathrm{b}}( \pm 14.65)$ \\
\hline W. anomalus + Fungamyl BrewQ & $33.23^{\mathrm{b}}( \pm 5.86)$ & $0.37^{\mathrm{a}}( \pm 0.14)$ & $67.74^{\mathrm{b}}( \pm 7.17)$ \\
\hline B. bruxellensis + Fungamyl BrewQ & $32.48^{\mathrm{b}}( \pm 1.66)$ & $3.34^{\mathrm{a}}( \pm 0.12)$ & $63.04^{\mathrm{b}}( \pm 8.72)$ \\
\hline M. pulcherrima+Fungamyl BrewQ & $21.29^{\mathrm{b}}( \pm 0.81)$ & $0.26^{\mathrm{a}}( \pm 0.07)$ & $43.67^{\mathrm{b}}( \pm 1.43)$ \\
\hline T. delbrueckii + Fungamyl BrewQ & $42.88^{\mathrm{a}}( \pm 7.64)$ & $0.65^{\mathrm{a}}( \pm 0.73)$ & $93.25^{\mathrm{b}}( \pm 5.65)$ \\
\hline
\end{tabular}




\section{CONCLUSIONS}

The non-Saccharomyces yeasts differed in the fermentation process rate. The yeast species allowed obtaining similar alcohol concentrations in beer to those obtained by $S$. cerevisiae. The use of enzymes added to the wort caused an increase in alcohol concentration in the obtained beers. Other tested parameters, such as total acidity, free amine nitrogen content, colour and sugar content indicate that the tested non-Saccharomyces yeast allow obtaining beers with the proper analytical properties. The use of enzymes added to the wort in most cases resulted in a higher fusels concentration in beers. The content of fatty acids in the analysed beers decreased after adding enzymes to the wort. The results obtained indicate the high potential of the tested strains in the brewing industry. Beers produced by the examined yeast strains, using enzymatic preparations can be used for the production of beer, not only low-alcohol ones.

\section{Conflict of interest}

All authors declare no conflicts of interest in this paper.

\section{Funding}

This work was supported by Grant LIDER [46/0185/L-9/17/NCBR/2018].

\section{REFERENCES}

1. Analytica EBC, 1998. European Brewery Convention. Verlag Hans Carl Getränke- Fachverlag, Nürnberg, Germany.

2. Barbosa, C., Lage, P., Esteves, M., Chambel, L., Mendes-Faia, A. \& Mendes-Ferreira, A. (2018). Molecular and phenotypic characterization of Metschnikowia pulcherrima strains from Douro wine region. Fermentation, 4(1), 8.DOI: 10.3390/fermentation4010008.

3. Basso, R.F., Alcarde, A.R. \& Portugal, C.B. (2016). Could non-Saccharomyces yeasts contribute on innovative brewing fermentations? Food Research International, 86, 112-120. DOI: 10.1016/j.foodres.2016.06.002.

4. Bellut, K. \& Arendt, E.K. (2019). Chance and Challenge: Non-Saccharomyces Yeasts in Nonalcoholic and Low Alcohol Beer Brewing-A Review. Journal of the American Society of Brewing Chemists, 77(2), 77-91. DOI: 10.1080/03610470.2019.1569452.

5. Birch, R.M. \& Walker, G.M. (2000). Influence of magnesium ions on heat shock and ethanol stress responses of Saccharomyces cerevisiae. Enzyme and Microbial Technology, 26(9-10), 678-687. DOI: 10.1016/S0141-0229(00)00159-9.

6. Briggs, D.E., Brookes, P.A., Stevens, R. \& Boulton, C.A. (2004). Brewing: science and practice. Woodhead Publishing Limited Cambridge London..

7. Callejo, M.J., González, C. \& Morata, A. (2017). Use of non-Saccharomyces yeasts in bottle fermentation of aged beers. Brewing Technology, 101-119. DOI: DOI: 10.5772/intechopen.68793.

8. Campbell, I. (2001). Kształtowanie właściwości sensorycznych piwa przez dobór warunków fermentacji. Przemyst Fermentacyjny i Owocowo-Warzywny, 8(45), 44-46.

9. Canonico, L., Agarbati, A., Comitini, F. \& Ciani, M. (2016). Torulaspora delbrueckii in the brewing process: A new approach to enhance bioflavour and to reduce ethanol content. Food Microbiology, 56, 45-51. DOI: 10.1016/j.fm.2015.12.005.

10. Canonico, L., Comitini, F. \& Ciani, M. (2017). Torulaspora delbrueckii contribution in mixed brewing fermentations with different Saccharomyces cerevisiae strains. International Journal of Food Microbiology, 259, 7-13. DOI: 10.1016/j.ijfoodmicro.2017.07.017.

11. Colicchio, T. (2012). The Oxford Companion to Beer. USA.

12. Contreras, A., Hidalgo, C., Henschke, P.A., Chambers, P.J., Curtin, C. \& Varela, C. (2014). Evaluation of non-Saccharomyces yeasts for the reduction of alcohol content in wine. Applied and Environmental Microbiology, 80(5), 1670-1678. DOI: 10.1128/AEM.03780-13.

13. Cordero-Bueso, G., Arroyo, T., Serrano, A. \& Valero, E. (2011). Influence of different floor management strategies of the vineyard on the natural yeast population associated with grape berries. International Journal of Food Microbiology, 148(1), 23-29. DOI: 10.1016/j.ijfoodmicro.2011.04.021.

14. Daniels, R. (1998). Designing great beers: The ultimate guide to brewing classic beer styles. Brewers Publications, Boulder, CO.

15. Dlamini, B.C., Buys, E.M. \& Taylor, J.R.N. (2015). Effect of sorghum type and malting on production 
of free amino nitrogen in conjunction with exogenous protease enzymes. Journal of the Science of Food and Agriculture, 95(2), 417-422. DOI: 10.1002/jsfa.6739.

16. Domizio, P., House, J.F., Joseph, C.M.L., Bisson, L.F. \& Bamforth, C.W. (2016). Lachancea thermotolerans as an alternative yeast for the production of beer. Journal of the Institute of Brewing, 122(4), 599-604. DOI: 10.1002/jib.362.

17. Ernandes, J.R., Williams, J.W., Russell, I. \& Stewart, G.G. (1993). Effect of yeast adaptation to maltose utilization on sugar uptake during the fermentation of brewer's wort. Journal of the Institute of Brewing, 99(1), 67-71. DOI: 10.1002/j.2050-0416.1993.tb01149.x.

18. Eßlinger, H.M. (2009). Handbook of brewing: processes, technology, markets. John Wiley \& Sons.

19. Evans, E., van Wegen, B., Ma, Y. \& Eglinton, J. (2003). The impact of the thermostability of $\alpha$ amylase, $\beta$-amylase, and limit dextrinase on potential wort fermentability. Journal of the American Society of Brewing Chemists, 61(4), 210-218. DOI: 10.1094/ASBCJ-61-0210.

20. Fix, G. (1999). Principles of brewing science: A study of serious brewing issues. Brewers Publications.

21. Hill, A.E. \& Stewart, G.G. (2019). Free Amino Nitrogen in Brewing. Fermentation, 5(1), 22. DOI: 10.3390/fermentation5010022.

22. King, A. \& Richard Dickinson, J. (2000). Biotransformation of monoterpene alcohols by Saccharomyces cerevisiae, Torulaspora delbrueckii and Kluyveromyces lactis. Yeast, 16(6), 499-506. DOI: 10.1002/(SICI)1097-0061(200004)16:6<499::AID-YEA548>3.0.CO;2-E.

23. Klein, M., Swinnen, S., Thevelein, J.M. \& Nevoigt, E. (2017). Glycerol metabolism and transport in yeast and fungi: established knowledge and ambiguities. Environmental Microbiology, 19(3), 878-893. DOI: 10.1111/1462-2920.13617.

24. MacDiarmid, C.W., Milanick, M.A. \& Eide, D.J. (2002). Biochemical Properties of Vacuolar Zinc Transport Systems of Saccharomyces cerevisiae. Journal of Biological Chemistry, 277(42), 3918739194. DOI: 10.1074/jbc.M205052200.

25. Matz, S.A. (1991). Chemistry and technology of cereals as food and feed. Springer Science \& Business Media.

26. Meneghin, M.C., Bassi, A.P.G., Codato, C.B., Reis, V.R. \& Ceccato-Antonini, S.R. (2013). Fermentative and growth performances of Dekkera bruxellensis in different batch systems and the effect of initial low cell counts in co-cultures with Saccharomyces cerevisiae. Yeast, 30(8), 295-305. DOI: 10.1002/yea.2959.

27. Michel, M., Kopecká, J., Meier-Dörnberg, T., Zarnkow, M., Jacob, F. \& Hutzler, M. (2016). Screening for new brewing yeasts in the non-Saccharomyces sector with Torulaspora delbrueckii as model. Yeast, 33(4), 129-144. DOI: 10.1002/yea.3146.

28. Muffler, K., Leipold, D., Scheller, M.-C., Haas, C., Steingroewer, J., Bley, T., Neuhaus, H.E., Mirata, M.A., Schrader, J. \& Ulber, R. (2011). Biotransformation of triterpenes. Process Biochemistry, 46(1),115. DOI: 10.1016/j.procbio.2010.07.015.

29. De Nicola, R. \& Walker, G.M. (2009). Accumulation and cellular distribution of zinc by brewing yeast. Enzyme and Microbial Technology, 44(4), 210-216. DOI: 10.1016/j.enzmictec.2008.11.008.

30. Nielsen, S. (2005). Handbook of food analysis, physical characterization and nutrient analysis. Journal of Food Quality, 28(5-6), 507-508.

31. Novozymes. Food\&Beverages. Brewing Handbook. (2013). Bagsvaerd.

32. Osburn, K., Amaral, J., Metcalf, S.R., Nickens, D.M., Rogers, C.M., Sausen, C., Caputo, R., Miller, J., Li, H. \& Tennessen, J.M. (2018). Primary souring: A novel bacteria-free method for sour beer production. Food microbiology, 70,76-84. DOI: 10.1016/j.fm.2017.09.007.

33. Padilla, B., Gil, J. V \& Manzanares, P. (2018). Challenges of the non-conventional yeast Wickerhamomyces anomalus in winemaking. Fermentation, 4(3), 68. DOI: 10.3390/fermentation4030068.

34. Poreda, A., Antkiewicz, P., Tuszyński, T. \& Makarewicz, M. (2009). Accumulation and release of metal ions by brewer's yeast during successive fermentations. Journal of the Institute of Brewing, 115(1), 7883. DOI: 10.1002/j.2050-0416.2009.tb00347.x.

35. Poreda, A., Bijak, M., Zdaniewicz, M., Jakubowski, M. \& Makarewicz, M. (2015). Effect of wheat malt on the concentration of metal ions in wort and brewhouse by-products. Journal of the Institute of Brewing, 121(2), 224-230. DOI: 10.1002/jib.226.

36. Procopio, S., Qian, F. \& Becker, T. (2011). Function and regulation of yeast genes involved in higher alcohol and ester metabolism during beverage fermentation. European Food Research and Technology, 233(5), 721-729. DOI: 10.1007/s00217-011-1567-9. 
37. Rees, E.M.R. \& Stewart, G.G. (1999). Effects of magnesium, calcium and wort oxygenation on the fermentative performance of ale and lager strains fermenting normal and high gravity worts. Journal of the Institute of Brewing, 105(4), 211-218. DOI: 10.1002/j.2050-0416.1999.tb00021.x.

38. Rollero, S., Bloem, A., Ortiz-Julien, A., Camarasa, C. \& Divol, B. (2018). Fermentation performances and aroma production of non-conventional wine yeasts are influenced by nitrogen preferences. FEMS Yeast Research, 18(5). DOI: 10.1093/femsyr/foy055.

39. Romano, P. \& Suzzi, G. (1993). Higher alcohol and acetoin production by Zygosaccharomyces wine yeasts. Journal of Applied Bacteriology, 75(6), 541-545. DOI: 10.1111/j.1365-2672.1993.tb01592.x.

40. Sadineni, V., Kondapalli, N. \& Obulam, V.S.R. (2012). Effect of co-fermentation with Saccharomyces cerevisiae and Torulaspora delbrueckii or Metschnikowia pulcherrima on the aroma and sensory properties of mango wine. Annals of Microbiology, 62(4), 1353-1360. DOI: 10.1007/s13213-011-03836.

41. Schifferdecker, A.J., Dashko, S., Ishchuk, O.P. \& Piškur, J. (2014). The wine and beer yeast Dekkera bruxellensis. Yeast, 31(9), 323-332. DOI: 10.1002/yea.3023.

42. Smith, B.D. \& Divol, B. (2016). Brettanomyces bruxellensis, a survivalist prepared for the wine apocalypse and other beverages. Food Microbiology, 59, 161-175. DOI: 10.1016/j.fm.2016.06.008.

43. Starcher, B. (2001). A ninhydrin-based assay to quantitate the total protein content of tissue samples. Analytical Biochemistry, 292(1), 125-129. DOI: 10.1006/abio.2001.5050.

44. Stehlik-Tomas, V., Gulan Zetić, V., Stanzer, D., Grba, S. \& Vahčić, N. (2004). Zinc, copper and manganese enrichment in yeast Saccharomyces cerevisae. Food Technology and Biotechnology, 42(2), 115-120. DOI: 10.1006/abio.2001.5050.

45. Szigeti, R., Miseta, A. \& Kellermayer, R. (2005). Calcium and magnesium competitively influence the growth of a PMR1 deficient Saccharomyces cerevisiae strain. FEMS Microbiology Letters, 251(2), 333-339. DOI: 10.1016/j.femsle.2005.08.017.

46. Tataridis, P., Drosou, F., Kanellis, A., Kechagia, D., Logothetis, S., Chatzilazarou, A. \& Dourtoglou, V. (2016). Differentiating beer aroma, flavor and alcohol content through the use of Torulaspora delbrueckii.

47. The National Institute of Standards and Technology (NIST). Available at: http://webbook.nist.gov/chemistry/ [2019-12-23]

48. Uscanga, M.G.A., Delia, M.-L. \& Strehaiano, P. (2003). Brettanomyces bruxellensis: effect of oxygen on growth and acetic acid production. Applied Microbiology and Biotechnology, 61(2), 157-162. DOI: 10.1007/s00253-002-1197-z.

49. Vanderhaegen, B., Delvaux, F., Daenen, L., Verachtert, H. \& Delvaux, F.R. (2007). Aging characteristics of different beer types. Food Chemistry, 103(2), 404-412. DOI: 10.1016/j.foodchem.2006.07.062.

50. Varela, C. \& Borneman, A.R. (2017). Yeasts found in vineyards and wineries. Yeast, 34(3), 111-128. DOI: 10.1002/yea.3219.

51. Verstrepen, K.J., Derdelinckx, G., Verachtert, H. \& Delvaux, F.R. (2003). Yeast flocculation: what brewers should know. Applied Microbiology and Biotechnology, 61(3), 197-205. DOI: 10.1007/s00253002-1200-8.

52. Vervoort, Y., Herrera-Malaver, B., Mertens, S., Guadalupe Medina, V., Duitama, J., Michiels, L., Derdelinckx, G., Voordeckers, K. \& Verstrepen, K.J. (2016). Characterization of the recombinant Brettanomyces anomalus $\beta$-glucosidase and its potential for bioflavouring. Journal of Applied Microbiology, 121(3), 721-733. DOI: 10.1111/jam.13200.

53. Wietstock, P.C., Kunz, T., Waterkamp, H. \& Methner, F.-J. (2015). Uptake and release of Ca, Cu, Fe, $\mathrm{Mg}$, and Zn during beer production. Journal of the American Society of Brewing Chemists, 73(2), 179184. DOI: 10.1094/ASBCJ-2015-0402-01.

54. Yeo, H.Q. \& Liu, S. (2014). An overview of selected specialty beers: Developments, challenges and prospects. International Journal of Food Science \& Technology, 49(7), 1607-1618. DOI: 10.1111/ijfs. 12488 .

55. Younis, O.S. \& Stewart, G.G. (1998). Sugar uptake and subsequent ester and higher alcohol production by Saccharomyces cerevisiae. Journal of the Institute of Brewing, 104(5), 255-264. DOI: 10.1002/j.2050-0416.1998.tb00998.x.

56. Zdaniewicz, M., Satora, P., Pater, A., Bogacz, S. (2020). Low lactic acid-producing strain of Lachancea thermotolerans as a new starter for beer production. Biomolecules, 256(10), 1-16. DOI: 10..3390/biom10020256. 
57. Zhao, X., Procopio, S. \& Becker, T. (2015). Flavor impacts of glycerol in the processing of yeast fermented beverages: a review. Journal of Food Science and Technology, 52(12), 7588-7598. DOI: 10.1007/s13197-015-1977-y.

58. Zironi, R., Romano, P., Suzzi, G., Battistutta, F. \& Comi, G. (1993). Volatile metabolites produced in wine by mixed and sequential cultures of Hanseniaspora guilliermondii or Kloeckera apiculata and Saccharomyces cerevisiae. Biotechnology Letters, 15(3), 235-238. DOI: 10.1007/BF00128311. 